\title{
Evidence-Based Consensus on Positioning of SGLT2i in Type 2 Diabetes Mellitus in Indians
}

\author{
Awadhesh Kumar Singh • Ambika G. Unnikrishnan · Abdul H. Zargar • \\ Ajay Kumar · Ashok K. Das · Banshi Saboo • Binayak Sinha • \\ Kalyan Kumar Gangopadhyay · Pradeep G. Talwalkar • \\ Samit Ghosal · Sanjay Kalra · Shashank Joshi · Surendra Kumar Sharma • \\ Usha Sriram • Viswanathan Mohan
}

Received: October 23, 2018 / Published online: January 31, 2019

(C) The Author(s) 2019

\section{ABSTRACT}

The current diabetes management strategies not only aim at controlling glycaemic parameters but also necessitate continuous medical care along with multifactorial risk reduction through a comprehensive management concept. The sodium-glucose cotransporter 2 inhibitors (SGLT2i) are a group of evolving antidiabetic agents that have the potential to play a pivotal role in the comprehensive management of patients with diabetes due to their

Enhanced Digital Features To view enhanced digital features for this article go to https://doi.org/10.6084/ m9.figshare.7546997.

\section{A. K. Singh $(\square)$}

GD Hospital and Diabetes Institute, Kolkata, West Bengal, India

e-mail: singhawadheshkumar2018@gmail.com

A. G. Unnikrishnan

Chellaram Diabetes Institute, Pune, Maharashtra, India

\section{A. H. Zargar}

Advanced Centre for Diabetes and Endocrine Care, Srinagar, Jammu and Kashmir, India

\section{A. Kumar}

Diabetes Care and Research Centre, Patna, Bihar, India

A. K. Das

Pondicherry Institute of Medical Sciences,

Pondicherry, India diverse beneficial effects. SGLT2i provide moderate glycaemic control, considerable body weight and blood pressure reduction, and thus have the ability to lower the risk of macrovascular and microvascular complications. Some of the unique characteristics associated with SGLT2i, such as reduction in body weight (more visceral fat mass loss than subcutaneous fat loss), reduction in insulin resistance and improvement in $\beta$-cell function, as measured by homeostatic model assessment- $\beta$ (HOMA- $\beta$ ) could be potentially beneficial and help in overcoming some of the challenges faced by Indian patients with diabetes. In addition, a patient-centric approach with individualised

B. Saboo

Diacare-Diabetes Care \& Hormone Clinic,

Ahmedabad, Gujarat, India

B. Sinha

AMRI Hospitals, Kolkata, West Bengal, India

K. K. Gangopadhyay

Fortis and Peerless Hospitals, Kolkata, West Bengal, India

P. G. Talwalkar

Talwalkar Diabetes Clinic, Mumbai, Maharashtra, India

S. Ghosal

Nightingale Hospital, Kolkata, West Bengal, India

S. Kalra

Bharti Hospital \& B.R.I.D.E, Karnal, Haryana, India 
treatment during SGLT2i therapy is inevitable in order to reduce diabetic complications and improve quality of life. Despite their broad benefits profile, the risk of genital tract infections, volume depletion, amputations and diabetic ketoacidosis associated with SGLT2i should be carefully monitored. In this compendium, we systematically reviewed the literature from Medline, Cochrane Library, and other relevant databases and attempted to provide evidence-based recommendations for the positioning of SGLT2i in the management of diabetes in the Indian population.

Funding: AstraZeneca Pharma India Limited.

Keywords: Dapagliflozin; Glycaemic efficacy; Indian population; SGLT2i; Type 2 diabetes

\section{EXECUTIVE SUMMARY}

\section{A. SGLT2i}

A1. SGLT2i decrease blood glucose concentration by reducing glucose reabsorption from proximal convoluted tubules and by increasing urinary glucose excretion (Grade A, Evidence Level [EL] 1)

A2. SGLT2i are associated with durable glycaemic efficacy, body weight and blood pressure (BP) reduction with cardiovascular benefits and renoprotective action without a higher risk of hypoglycaemia (Grade A, EL 2)

A3. Treatment with SGLT2i is associated with side-effects such as genital tract

S. Joshi

Lilavati Hospital and Research Centre, Mumbai,

Maharashtra, India

S. K. Sharma

Galaxy Speciality Centre, Jaipur, Rajasthan, India

U. Sriram

Clinical Endocrinology Education and Research

(ACEER), Chennai, Tamil Nadu, India

V. Mohan

Dr Mohan's Diabetes Specialities Centre and Madras

Diabetes Research Foundation, Chennai, Tamil

Nadu, India infections (GTIs) and volume depletion-related adverse events; however, these can be minimised with proper education and counselling with close patient monitoring (Grade A, EL 2)

A4. Body weight, A1C and systolic BP are important parameters that can be used to identify non-responders to SGLT2i therapy (Grade B, EL2)

A5. Treatment with SGLT2i results in persistent calorie loss, which leads to weight loss. There is also some evidence of a reduction in $\beta$-cell stress and hyperinsulinaemia, and an increase in insulin sensitivity and the rate of insulin secretion (Grade C, EL 4).

B. SGLT2i: Monotherapy

B1. SGLT2i as monotherapy reduce HbA1c, fasting plasma glucose (FPG), body weight and BP in patients with type 2 diabetes mellitus (T2DM); however, the risk of GTIs, especially in women, should be carefully monitored (Grade A, EL 1)

B2. SGLT2i can be used as monotherapy if metformin is contradicted or not tolerated (Grade A, EL 1)

B3. SGLT2i are associated with superior A1C reduction compared to DPP4 inhibitors (DPP4i), especially in marked hyperglycaemia, but have a similar effect as metformin and sulphonylureas. However, body weight and BP reduction abilities of SGLT2i are superior to metformin, sulphonylureas and DPP4i (Grade A, EL1).

C. SGLT2i: Dual Therapy

C1. In T2DM patients with unmet needs of glycaemic control with metformin monotherapy, SGLT2i are a preferred option as a second-line agent (Grade A, EL 1)

C2. SGLT2i as monotherapy and as an addon to metformin effectively reduce A1C, FPG, body weight and BP in patients with T2DM (Grade A, EL 1)

C3. In patients with T2DM, SGLT2i provide long-term glycaemic efficacy that 
is superior to DPP4 $\mathrm{i}$ and sulfonylureas (Grade A, EL 1)

C4. Compared to sulfonylureas, SGLT2i as a second-line agent are associated with non-inferior glycaemic control with a significant reduction in body weight, BP and rates of hypoglycaemia (Grade A, EL 1)

C5. When used as a second-line agent after metformin, SGLT2i are more effective in terms of glycaemic control, body weight, and $\mathrm{BP}$ reduction compared to DPP4i (Grade A, EL 1)

C6. SGLT2i significantly reduce the risk of cardiovascular morbidity and mortality (Grade A, EL 1)

C7. SGLT2i are associated with renoprotective effects such as slower progression to kidney disease and progression of albuminuria, and reduction of estimated glomerular filtration rate (eGFR) in patients with T2DM (Grade A, EL 1).

D. SGLT2i: Miscellaneous Effects

D1. SGLT2i improve insulin sensitivity and $\beta$-cell function and reduce insulin resistance and are therefore recommended in insulin-resistant T2DM patients (Grade A, EL 2)

D2. When combined with insulin, SGLT2i may decrease the cost of insulin treatment by reducing daily insulin dose requirements (Grade B, EL 3)

D3. Treatment with SGLT2i may reduce the level of uric acid and decrease albuminuria; thus, they might decrease diabetic complications in patients with T2DM (Grade B, EL 3).

E. SGLT2i: Safety, Tolerability and Contraindications

E1. The risk of hypoglycaemia in patients with T2DM is lower with SGLT2i than with insulin secretagogues and insulin. Patients taking a combination of SGLT2i and insulin or insulin secretagogues should be closely monitored (Grade A, EL1)

E2. SGLT2i are associated with a higher rate of GTIs than other antidiabetic drugs; however, differences in the incidence of urinary tract infections (UTIs) between SGLT2i and other antidiabetic drugs are inconsistently reported (Grade A, EL1).

E3. SGLT2i may be associated with volume depletion or osmotic diuresis-related adverse events compared to other antidiabetic drugs (Grade A, EL1)

E4. There is insufficient evidence to suggest causality between SGLT2i and an increased risk of bone fracture and osteoporosis in patients with T2DM. Treatment should be individualised in high-risk patients (older patients, with a prior history/risk of cardiovascular disease) (Grade A, EL1)

E5. SGLT2i (canagliflozin; CANA) are associated with an increased risk of peripheral vascular disease/amputation (Grade A, EL1)

E6. SGLT2i are contraindicated in patients with an eGFR of $<45 \mathrm{~mL} / \mathrm{min} / 1.73 \mathrm{~m}^{2}$, extreme insulinopaenia or type 1 diabetes, on a fluid/carbohydrate restricted diet, or with decompensated medi$\mathrm{cal} /$ surgical illness, pregnancy, lactation and in children (Grade A, EL1).

F. SGLT2i: Indian Phenotype

F1. SGLT2i are emerging agents that can provide multiple benefits in Indian diabetes patients (Grade B, EL 3)

F2. The weight reduction associated with SGLT2i is due to loss of fat mass primarily from the abdomen rather than lean mass (Grade A, EL 2)

F3. The benefits associated with SGLT2i such as improvement of $\beta$-cell function and reduction of insulin resistance may be more useful in Indian patients with diabetes (Grade A, EL 2).

\section{INTRODUCTION}

Diabetes mellitus (DM) is a complex and chronic disorder that necessitates continuous medical care along with multifactorial risk reduction strategies beyond glycaemic control 
[1]. The endemic nature of the disease is continuously increasing the global disease burden and affecting the patient's quality of life (QoL). According to the recent International Diabetes Federation (IDF) 2017 estimates, the global prevalence of diabetes in patients aged 20-79 years is $8.8 \%$ (425 million), which may rise to $9.9 \%$ (629 million) by 2045 [2]. Astonishingly, India has the second largest population with diabetes in the world with an estimated 69.2 million in 2017 and may overtake China (currently positioned first place) by 2045 with an estimated population with diabetes of 134.3 million [3]. Moreover, large-scale surveys such as the District Level Household and Facility Survey (DLHS) 2012-2013, and the Annual Health Survey (AHS) 2014 reported that around $7 \%$ of Indian adults are suffering from diabetes and the prevalence is higher in urban areas $(9.8 \%)$ than in rural areas (5.7\%) [4].

The World Health Organization (WHO) has reported that overweight and obesity are the strongest risk factors for diabetes, and people from high- and middle-income countries have a two-fold higher prevalence of overweight and obesity than low-income countries [5]. In addition, the STEPwise approach to Surveillance of non-communicable diseases (STEPS) survey from India reports that hypertension, obesity and family history of diabetes are significant risk factors associated with DM [6]. Several studies reported that approximately $30-70 \%$ of patients fail to achieve target glycaemic control in spite of treatment [7, 8]. Furthermore, a recent study from India estimated that only 9\% of type $2 \mathrm{DM}$ (T2DM) patients are achieving A1C, blood pressure (BP), and cholesterol (ABC) goals [9]. Uncontrolled DM leads to several microvascular and macrovascular complications and among these, cardiovascular (CV) complications are the most common causes of death and disability [10]. Moreover, the risk of stroke or coronary artery disease (CAD) also doubles in diabetes patients who are overweight [11].

Therefore, a comprehensive management concept comprising of (a) the achievement of glycaemic targets, (b) the reduction of the risk of diabetes-associated macrovascular and microvascular complications, (c) approaches for reduction of weight and obesity, (d) the reduction of blood pressure (BP) and lipid levels, and (e) improvement of patient compliance, is highly obligatory in the management of T2DM [5]. Sodium-glucose cotransporter 2 inhibitors (SGLT2i), pertaining to their relative glycaemic efficacy, weight and BP reduction, lipid level regulation, and lowering the risk of macrovascular and microvascular complications, could be a better drug of choice in the current era of diabetes management. The scope of this consensus is to review and provide evidencebased recommendations for the positioning of SGLT2i in the management of diabetes in the Indian population.

\section{METHODOLOGY}

The recommendations in the current consensus document were developed in accordance with the American Association of Clinical Endocrinologists (AACE) protocol for the standardised production of clinical practice guidelines after reviewing the recent evidence on SGLT2i [12]. A thorough review of the literature was initiated in Medline, Cochrane Library, and other related databases to impart the highest possible evidence base for the use of SGLT2i in the management of T2DM. Existing guidelines, metaanalyses, systematic reviews, randomised controlled trials (RCTs), non-RCTs, and key articles related to T2DM management were reviewed and recommendations were framed. The recommendations for each section of the consensus statement were discussed by expert panels and where there was a little or no evidence, the panel relied on logical empiricism and consensus to make the recommendations. The recommendations are based on clinical importance (Grade A: strong, B: intermediate, C: weak, and D: no evidence available), which were coupled with four intuitive levels of evidence $(1=$ at least one RCT or meta-analysis of RCTs, $2=$ at least one non-randomised or non-controlled, prospective epidemiological study, $3=$ crosssectional or observational or surveillance or pilot study and $4=$ existing guideline or consensus expert opinion on extensive patient experience or review) (Table 1). 
Table 1 Evidence and recommendation grading [12]

\begin{tabular}{llll}
\hline $\begin{array}{l}\text { Evidence } \\
\text { level }\end{array}$ & Semantic descriptor (reference methodology) & Grades & Recommendation \\
\hline 1 & $\begin{array}{l}\text { Meta-analysis of randomised controlled trials, Randomised controlled trials } \\
2\end{array}$ & A & Strong \\
& $\begin{array}{l}\text { Meta-analysis of non-randomised prospective or case-controlled trials, non- } \\
\text { randomised controlled trial, prospective cohort study, retrospective } \\
\text { case-control study }\end{array}$ & B & Intermediate \\
3 & $\begin{array}{l}\text { Cross-sectional study, surveillance study (registries, surveys, epidemiologic study, } \\
\text { retrospective chart review, mathematical modelling of database), consecutive } \\
\text { case series, single case reports }\end{array}$ & Weak & \\
& No evidence (theory, opinion, consensus, review, or preclinical study) & D & No evidence \\
\hline
\end{tabular}

\section{Compliance with Ethics Guidelines}

This article is based on previously conducted studies and does not contain any studies with human participants or animals performed by any of the authors.

\section{SGLT2I AND DIABETES}

\section{SGLT2I}

SGLT2i are a promising novel class of glucoselowering agents that interrupt the metabolic pathway without impairing $\beta$-cell function and insulin resistance [13]. Phlorizin, the first SGLT2i, was a naturally occurring substance obtained from apple tree bark. However, since it was nonselective and has poor oral bioavailability, work on its development could not continue [14]. Subsequently, selective drugs that inhibit SGLT2 receptor have now been developed.

Dapagliflozin (DAPA), canagliflozin (CANA), empagliflozin (EMPA), and recently ertugliflozin, are the four SGLT2i that have been approved by the European Medicines Agency (EMA) and the Food and Drug Administration (FDA) either as monotherapy or as an add-on to other antidiabetic agents [15]. Ipragliflozin, luseogliflozin, and tofogliflozin are approved only in Japan [16]; sotagliflozin and remogliflozin are in the clinical development stage [15].

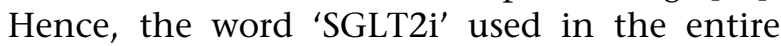
consensus document will represent only DAPA, CANA, and EMPA. Details regarding approval, pharmacokinetic/pharmacodynamic profiles, contradictions, and dose adjustment required for different SGLT2i are described in Table 2 $[13,17-22]$.

\section{Mechanism of Action}

SGLT2i act on glucose metabolism and homeostasis through regulating the kidney function. The kidneys play a vital role in glucose homeostasis via three processes such as renal gluconeogenesis, glomerular filtration, and glucose reabsorption in the proximal convoluted tubule (PCT) [23]. In a healthy individual, the kidney can filter around $180 \mathrm{~g}$ of glucose daily; all of this glucose is reabsorbed in the PCT ( 90\% reabsorption occurs from the S1 segment while $\sim 10 \%$ reabsorption occurs from the S2/ S3 segments of PCT). This reabsorption process in the PCT is generally mediated by the SGLT receptor family (6 members, SGLT 1-6). Details of the SGLT family members are given in Table 3 [13, 15]. Among the SGLT receptor family, SGLT2 receptor is found in the S1 segment and SGLT1 receptor is found in the S2/S3 segment of the PCT. All of the reabsorbed glucose is then transported back into circulation by a passive transport mechanism through facilitative glucose transporters; as a result, the glucose concentration in the plasma increases $[13,24]$. The mechanisms of action of SGLT2i and their effect on various physiological parameters are depicted in Fig. 1 [13, 25]. 
Table 2 Details regarding approvals, pharmacokinetic/pharmacodynamic profiles, contradictions, and dose adjustment required for different SGLT2i [13, 17-22]

\begin{tabular}{|c|c|c|c|}
\hline & Canagliflozin & Dapagliflozin & Empagliflozin \\
\hline $\begin{array}{l}\text { US-FDA } \\
\text { approval }\end{array}$ & March, 2013 & January, 2014 & August, 2014 \\
\hline DCGI approval & November 2014 & February 2015 & August 2015 \\
\hline Dosage (range) & $100-300 \mathrm{mg}$ daily & 5-10 mg daily & $10-25 \mathrm{mg}$ daily \\
\hline Absorption & $\begin{array}{l}\text { Time to peak in plasma: } 1 \text { to } \\
2 \mathrm{~h}\end{array}$ & Time to peak in plasma: $2 \mathrm{~h}$ & Time to peak in plasma: $1.5 \mathrm{~h}$ \\
\hline $\mathrm{V}_{\mathrm{d}}(\mathrm{L})$ & 83.5 & 118 & 73.8 \\
\hline $\begin{array}{l}\text { Protein binding } \\
(\%)\end{array}$ & 99 mainly to albumin & 91 & 86.2 \\
\hline Metabolism & $\begin{array}{l}\text { O-glucuronidation by } \\
\text { UGT1A9 and UGT2B4 }\end{array}$ & $\begin{array}{l}\text { O-glucuronidation by UGT1A9; } \\
\text { CYP-mediated metabolism } \\
\text { (minor) }\end{array}$ & $\begin{array}{l}\text { O-glucuronidation by UGT2B7, } \\
\text { UGT1A3, UGT1A8, and } \\
\text { UGT1A9 }\end{array}$ \\
\hline Excretion & Faeces $>$ urine & Urine $>$ faeces & Urine $>$ faeces \\
\hline $\begin{array}{l}\text { Bioavailability } \\
\text { (\%) }\end{array}$ & 65 & 78 & 78 \\
\hline Half-life (h) & $10.6-13.1$ & 12.9 (10 mg dose $)$ & 12.4 \\
\hline $\begin{array}{l}\text { Onset of action } \\
\text { (h) }\end{array}$ & Within $24 \mathrm{~h}$ (dose-dependent) & & \\
\hline $\begin{array}{r}\text { Duration of } \\
\text { action }(\mathrm{h})\end{array}$ & 24 & & \\
\hline $\begin{array}{l}\text { Drug-drug } \\
\text { interaction }\end{array}$ & $\begin{array}{l}\uparrow \text { Efficacy: alpha lipoic acid, } \\
\text { heparin guanethidine, MAO } \\
\text { inhibitors, salicylates } \\
\downarrow \text { Efficacy: carbamazepine, } \\
\text { efavirenz, phenytoin, } \\
\text { rifampicin, ritonavir }\end{array}$ & $\begin{array}{l}\uparrow \text { Efficacy: alpha lipoic acid, } \\
\text { MAO inhibitors, salicylates, } \\
\text { quinolone antibiotics, SSRIs } \\
\downarrow \text { Efficacy: rifampicin, diuretics, } \\
\text { NSAIDs }\end{array}$ & $\begin{array}{l}\uparrow \text { Efficacy: alpha lipoic acid, } \\
\text { MAO inhibitors, salicylates, } \\
\text { quinolone antibiotics, SSRIs } \\
\downarrow \text { Efficacy: rifampicin, diuretics, } \\
\text { NSAIDs }\end{array}$ \\
\hline Contraindications & History of serious hypersensitivi & ty, severe renal impairment (eGFR & $\left.<30 \mathrm{~mL} / \mathrm{min} / 1.73 \mathrm{~m}^{2}\right), \mathrm{ESRD}$ \\
\hline $\begin{array}{l}\text { Dose adjustment } \\
\text { in hepatic } \\
\text { impairment }\end{array}$ & $\begin{array}{l}\text { Mild-to-moderate } \\
\text { (Child-Pugh class A, B): no } \\
\text { dosage adjustment } \\
\text { Severe (Child-Pugh class C): } \\
\text { use not recommended }\end{array}$ & $\begin{array}{l}\text { No dosage adjustment necessary; } \\
\text { use caution if initiating in } \\
\text { severe impairment }\end{array}$ & No dosage adjustment \\
\hline
\end{tabular}


Table 2 continued

\begin{tabular}{llcc}
\hline & Canagliflozin & Dapagliflozin & Empagliflozin \\
\hline $\begin{array}{l}\text { Dose adjustment } \\
\text { in renal }\end{array}$ & eGFR $\geq 60 \mathrm{~mL} / \mathrm{min} / 1.73 \mathrm{~m}^{2}:$ & eGFR $\geq 45 \mathrm{~mL} / \mathrm{min} / 1.73 \mathrm{~m}^{2}:$ & eGFR $\geq 45 \mathrm{~mL} / \mathrm{min} / 1.73 \mathrm{~m}^{2}:$ \\
impairment & no dosage adjustment & no dosage adjustment & no dosage adjustment \\
& eGFR $45-60 \mathrm{~mL} / \mathrm{min} /$ & eGFR $<45 \mathrm{~mL} / \mathrm{min} / 1.73 \mathrm{~m}^{2}:$ & $\mathrm{eGFR}<45 \mathrm{~mL} / \mathrm{min} / 1.73 \mathrm{~m}{ }^{2}:$ \\
& $\begin{array}{l}1.73 \mathrm{~m}^{2}: 100 \mathrm{mg} \text { once daily } \\
\text { (maximum) }\end{array}$ & not recommended & not recommended \\
\hline
\end{tabular}

USFD $A$ United Stated Food and Drug Administration, DCGI Drugs Controller General of India, $m g$ milligram, $b$ hours, $V d$ Volume of distribution, UGT Uridine 5'-diphospho-glucuronosyltransferase, CYP Cytochrome P450, MAO Monoamine oxydase, SSRI Selective serotonin reuptake inhibitor, NSAIDs Non-steroidal anti-inflammataory drugs, eGFR estimated glomerular filtration rate, ESRD end stage renal disease

Table 3 Characteristics of SGLT family $[13,15]$

\begin{tabular}{|c|c|c|c|c|c|}
\hline $\begin{array}{l}\text { SGLT } \\
\text { family }\end{array}$ & Gene & Substrate & Distribution in tissue & Function & Expression \\
\hline SGLT1 & $S L C 5 A 1$ & $\begin{array}{l}\text { Glucose, } \\
\text { galactose }\end{array}$ & $\begin{array}{l}\text { Small intestine, kidney (S3 segment of } \\
\text { PCT), trachea, heart, brain, testis, } \\
\text { prostate }\end{array}$ & $\begin{array}{l}\text { Transportation of } \\
\text { glucose/galactose }\end{array}$ & Intestine $>$ kidney \\
\hline SGLT2 & $S L C 5 A 2$ & Glucose & $\begin{array}{l}\text { Kidney (S1 and S2 segment of PCT), brain, } \\
\text { liver, thyroid, muscle, heart }\end{array}$ & $\begin{array}{l}\text { Transportation of } \\
\text { glucose and } \\
\text { sodium }\end{array}$ & $\begin{array}{l}\text { Mainly found in } \\
\text { kidney }\end{array}$ \\
\hline SGLT3 & SLC5A4 & Glucose & Intestine, testis, uterus, lung, brain, thyroid & Glucose sensor & - \\
\hline SGLT4 & SLC5A9 & $\begin{array}{l}\text { Glucose, } \\
\text { mannose }\end{array}$ & $\begin{array}{l}\text { Intestine, kidney, liver, brain, lung, trachea, } \\
\text { uterus, pancreas }\end{array}$ & $\begin{array}{l}\text { Transportation of } \\
\text { glucose and } \\
\text { mannose }\end{array}$ & - \\
\hline SGLT5 & SLC5A10 & $\begin{array}{l}\text { Glucose, } \\
\text { galactose }\end{array}$ & Kidney & Unknown & - \\
\hline SGLT6 & SLC5A11 & $\begin{array}{l}\text { D-chiro- } \\
\text { inositol }\end{array}$ & Spinal cord, kidney, brain & $\begin{array}{l}\text { Absorption of } \\
\text { glucose }\end{array}$ & - \\
\hline
\end{tabular}

SGLT sodium-glucose cotransporter, SLC Sodium carrier family, PCT proximal convoluted tubule

The SGLT2i selectively inhibit the SGLT2 receptors and reduce glucose reabsorption in the PCT, and thereby lower hyperglycaemia by increasing urinary glucose excretion (UGE). Furthermore, SGLT2i therapy results in persistent calorie loss that leads to weight loss, $\beta$-cell stress reduction and hyperinsulinaemia, increased insulin sensitivity and rate of insulin secretion. Consecutively, all these mechanisms continuously regulate blood glucose despite insulin resistance or $\beta$-cell dysfunction $[13,26-30]$. In addition, SGLT2i may also be effective in the advanced stages of T2DM (when pancreatic $\beta$ cell reserves are permanently lost) due to their insulin-independent mechanism of action [31].

\section{Place in Therapy}

SGLT2i are the most recent addition to the T2DM management armamentarium. They have some adjunct advantages such as weight 


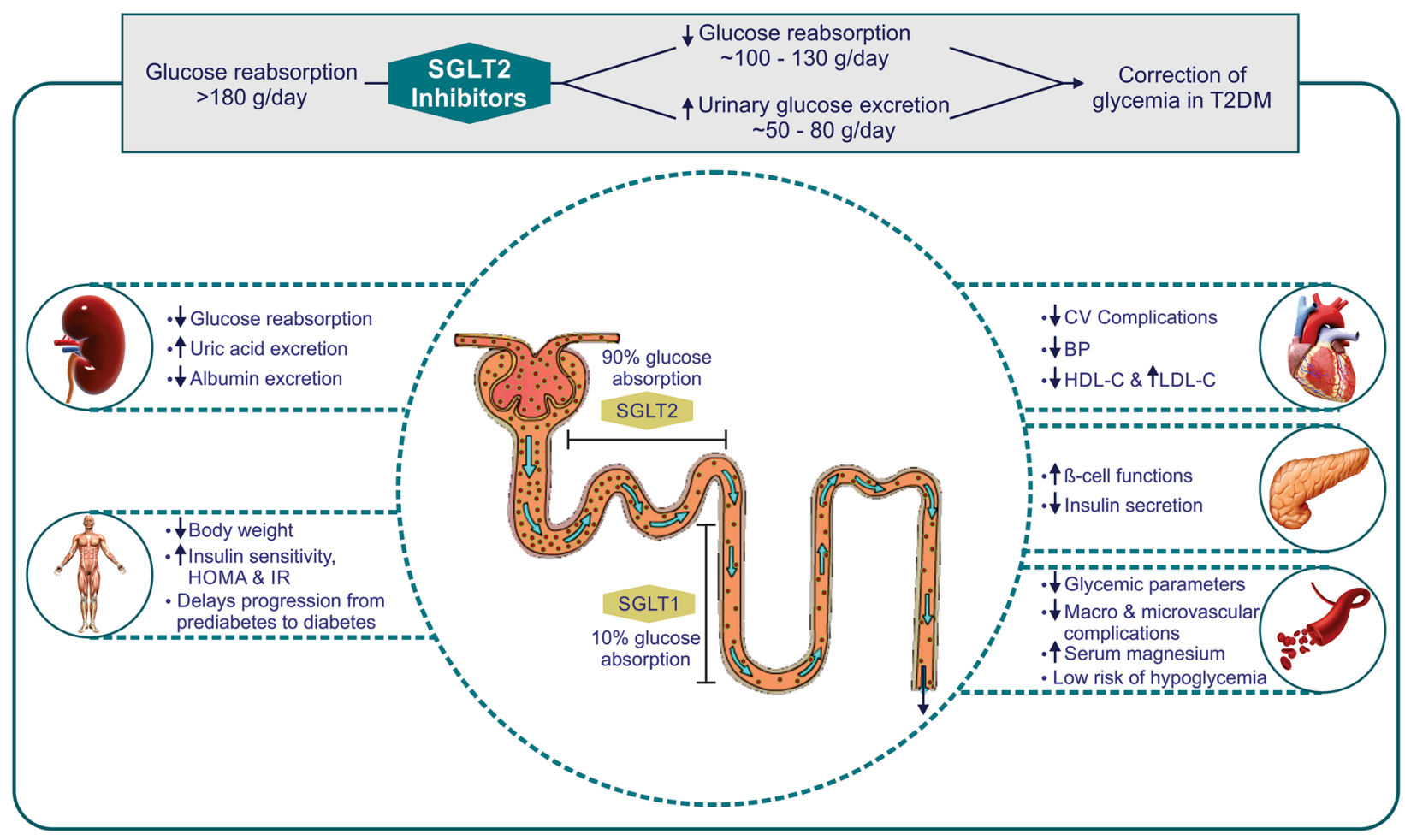

Fig. 1 Mechanisms of action of SGLT2i and their effect on the physiological system in the human body $[13,25]$. $B P$ blood pressure, $C V$ cardiovascular, $H D L-C$ highdensity lipoprotein cholesterol, HOMA homeostatic model assessment, $L D L-C$ low-density lipoprotein cholesterol, $I R$ insulin resistance, $I S$ insulin sensitivity, SGLT sodium glucose co-transporter, T2DM type 2 diabetes mellitus, $\uparrow$

and $\mathrm{BP}$ reduction, low risk of hypoglycaemia, and reduction in macrovascular and microvascular events [32]. Moreover, these drugs may also rectify some core defects like improvement in $\beta$-cell function and insulin sensitivity in T2DM patients. However, they also have several adverse effects, especially genital tract infections (GTIs), volume depletion, toe amputation and diabetic ketoacidosis [32]. Pertaining to their potential advantages, several guidelines have placed SGLT2i in both monotherapy and combination therapy in the management of T2DM (Table 4) [1, 33-39].

\section{Responders to SGLT2i}

Body weight, A1C, and systolic BP are the various parameters used to determine the increase, $\downarrow$ decrease. Reproduced with permission from Kalra. S, Ghosh. S, Aamir. A.H, et al. Safe and pragmatic use of sodium-glucose co-transporter 2 inhibitors in type 2 diabetes mellitus: South Asian Federation of Endocrine Societies consensus statement. Indian J Endocrinol Metab. 2017; 21:210-230

responders/non-responders to SGLT2 $\mathrm{i}$ treatment in various studies [40-43]. In a post hoc analysis of two double-blind RCTs, patients in the SGLT2i treatment arm who had a 12-week A1C or systolic BP change lower than the median were considered as an A1C or systolic $\mathrm{BP}$ responder; a non-responder was defined as a 12-week A1C or systolic BP change on or above the median [40]. Similarly, in a retrospective study, SGLT2i-treated patients who had $\geq 5 \%$ body weight reduction were classified as responders and those with $<5 \%$ body weight reduction were classified as non-responders [43]. Moreover, baseline fasting C-peptide level was the important factor influencing change in body weight; it was found to be higher in the responder group than in the non-responder group $(3.25 \pm 1.07$ vs $2.62 \pm 1.02 \mathrm{ng} / \mathrm{mL}$, $P=0.023)$ [43]. 


\section{Recommendation: SGLT2i}

- SGLT2i decrease blood glucose concentration by reducing glucose reabsorption from the PCT and by increasing UGE (Grade A, EL 1)

- SGLT2i are associated with durable glycaemic efficacy, body weight and $\mathrm{BP}$ reduction with $\mathrm{CV}$ benefits and renoprotective action without a higher risk of hypoglycaemia (Grade A, EL 2)

- Treatment with SGLT2i is associated with side-effects such as GTIs and volume depletion-related adverse events; however, these can be minimised with proper education and counselling with close patient monitoring (Grade A, EL 2)

- Body weight, A1C and systolic BP are important parameters that can be used to identify non-responders to SGLT2i therapy (Grade B, EL2)

- Treatment with SGLT2i results in persistent calorie loss, which leads to weight loss. There is also some evidence of a reduction in $\beta$-cell stress and hyperinsulinaemia, and an increase in insulin sensitivity and the rate of insulin secretion (Grade C, EL 4)

\section{Clinical Efficacy}

Evidence from numerous clinical trials, systematic reviews, and meta-analyses suggests that SGLT2i as monotherapy are effective and safe in controlling glycaemic parameters in patients with T2DM.

A systematic review and network meta-analysis (NMA) including 38 RCTs (23,997 participants with a duration of $\geq 24$ weeks) investigated the efficacy of SGLT2i in patients with T2DM. Compared to placebo, all SGLT2i reduced $\mathrm{A} 1 \mathrm{C}(-0.6 \%$ to $-0.9 \%)$, fasting plasma glucose (FPG) ( -1.1 to $-1.9 \mathrm{mmol} / \mathrm{l})$, body weight ( -1.6 to $-2.5 \mathrm{~kg}$ ), and $\mathrm{BP}$ (systolic -4.9 to $-2.8 \mathrm{mmHg}$; diastolic -2.0 to $-1.5 \mathrm{mmHg}$ ) [44]. However, more hypoglycaemic episodes were reported with CANA than DAPA. Moreover, GTI episodes (odds ratios [OR] 4-6) are reported to be higher with SGLT2i compared to placebo [44]. Recently, a systematic review and NMA by Johnston et al. reported that SGLT2i as monotherapy significantly improved glycaemic parameters, induced weight loss, and reduced BP [45]. All RCTs included in this study were of $\geq 24$ weeks. Compared to placebo or active comparator, SGLT2i reduced A1C $(P<0.001)$, body weight $(P<0.001)$, lipid level $(P<0.01)$, and BP $(P<0.001)$ in patients with T2DM [45]. All RCTs reported a 4-9\% increase in urinary tract infections (UTIs) and GTIs with SGLT2i treatment mainly in women. In line with the evidence, another systematic review and metaanalysis including 39 RCTs (25,468 patients) reported that SGLT2i were associated with better glycaemic control (A1C reduction $-1.01 \%$ to $-0.51 \%)$, weight loss $(-2.66$ to $-1.80 \mathrm{~kg})$, and $\mathrm{BP}$ reduction (systolic -4.77 to $-2.66 \mathrm{mmHg}$; diastolic -1.99 to $-1.76 \mathrm{mmHg}$ ) compared to placebo [46]. Similarly, a meta-analysis including placebo-controlled trials reported that SGLT2i were associated with an A1C reduction of $0.5 \%, 0.6 \%$ and $0.6 \%$ at 12,24 and 52 weeks, respectively [47]. Furthermore, several 
Table 4 Place of SGLT2i in therapy by various guidelines

American College of Physicians (ACP) 2017 [33]

National Institute for Health and Care Excellence (NICE) 2017 [34]

International Diabetes Federation (IDF) 2017 [35]

American Diabetes Association (ADA) 2018 [1]

AACE 2017 [36]

Diabetes Canada Clinical Practice Guidelines 2018 [37]

Stable coronary artery disease (SCAD) management protocols in India 2016 [38]

Research Society for the Study of Diabetes in India (RSSDI) 2017 [39]
Recommends addition of either SU/TZD/SGLT2i/DPP4i to metformin to improve glycaemic control when a second oral therapy is considered

Combinations of metformin and SGLT2i reduce weight more than metformin monotherapy

SGLT2i, as monotherapy or with metformin, reduce SBP more than metformin monotherapy

As a first line agent, SGLT-2i instead of DPP4i should be preferred if an $\mathrm{SU} / \mathrm{TZD}$ is not appropriate

If $\mathrm{AlC}>7.5 \%$, DPP4i/SU/TZD/SGLT2i can be used as a second-line or third-line agent

The preferred combinations may be metformin + SU, DPP4i or SGLT2i

Recently SGLT2i have been considered as an option to add to metformin + SU or metformin + DPP4i combination

If $\mathrm{A} 1 \mathrm{C}>9 \%$, consider dual therapy

If A1C target not achieved in 3 months, proceed to triple therapy

SGLT2i along with other antidiabetic drugs can be used as dual or triple therapy

If entryA $1 \mathrm{C}<7.5 \%$, consider monotherapy

If entry $\mathrm{A} 1 \mathrm{C} \geq 7.5 \%$, consider dual and triple therapies

SGLT2i placed before DPP4i, SU, and TZD in mono, dual, and triple therapies

If A1C $>1.5 \%$ above target, incretins and/or SGLT2i should be considered if lower risk of hypoglycaemia and/or weight gain are priorities

In adults with T2DM, on insulin, with inadequate glycaemic control, SGLT2i should be considered as an add-on therapy to improve glycaemic control with weight loss and lower hypoglycaemic risk compared to additional insulin

All SCAD patients with diabetes should be treated with oral antidiabetics which have shown CV safety/benefits such as metformin, gliclazide, gliptins, SGLT2i

SGLT2i can be considered as a second-line agent when glucose targets are not being achieved

SGLT2i can be considered as a third-line agent along with AGIs, DPP4i, or TZD

$S U$ sulphonylureas, $T Z D$ thiazolidinediones, $S G L T 2 i$ sodium-glucose cotransporter 2 inhibitors, DPP4i dipeptidyl peptidase 4 inhibitors, $A I C$ Hemoglobin A1C, AACE American Association of Clinical Endocrinologists 
systematic reviews and meta-analyses of RCTs reported that SGLT2i as monotherapy were efficacious, reduced body weight and BP, and were well tolerated by T2DM patients [48-52]. In addition, several RCTs also reported that SGLT2i
- $4.43 \mathrm{mmHg}$, respectively) [46]. Details of the studies comparing SGLT2i with placebo are given in Table 5 [54, 55, 57-60].

\section{Recommendation: Monotherapy}

- SGLT2i as monotherapy reduce A1C, FPG, body weight and BP in patients with T2DM; however, the risk of GTIs in women should be carefully monitored (Grade A, EL 1)

- SGLT2i can be used as monotherapy if metformin is contradicted or not tolerated (Grade A, EL 1)

- SGLT2i are associated with superior A1C reduction compared to DPP4i, especially in marked hyperglycaemia, but have a similar effect as metformin and sulphonylureas. However, body weight and BP reduction abilities of SGLT2 $\mathrm{i}$ are superior to metformin, sulphonylureas and DPP4i (Grade A, EL1)

were associated with clinically meaningful improvements in glycaemic parameters, and a reduction in body weight and $\mathrm{BP}$ in patients with baseline $\mathrm{A} 1 \mathrm{C} \geq 9 \%$ or $\geq 10 \%$ [53-55].

Monotherapy with SGLT2i has been found to be effective and safe compared to other antidiabetic agents. A systematic review and metaanalysis including 25 RCTs reported that SGLT2i were associated with a significantly higher reduction in A1C (weighted mean difference $[\mathrm{WMD}] 0.13 \%, P=0.005)$ and $\mathrm{FPG}$ (WMD $0.80 \mathrm{mmol} / \mathrm{L}, P<0.00001$ ) than DPP4 inhibitors (DPP4i) [56]. However, there was no significant difference of hypoglycaemic risk between the treatments (RR 0.99; $P=0.92$ ). Another systematic review and meta-analysis including 39 RCTs $(25,468$ patients) reported that SGLT2i were similar to metformin and sulphonylureas, but superior to DPP4i (- $0.15 \%)$ regarding A1C reduction, and were better than metformin, sulphonylureas, and DPP4i in lowering body weight $(-1.04 \mathrm{~kg}$, - $4.76 \mathrm{~kg}$ and $-2.45 \mathrm{~kg}$ ) and systolic BP reduction $(-5.86 \mathrm{mmHg}$, $-5.44 \mathrm{mmHg}$, and
POSITIONING OF SGLT2I

IN TREATMENT CONTINUUMFOCUS ON AFTER METFORMIN

\section{Glycaemic Efficacy}

\section{SGLT2i vs Placebo}

In unmet needs of glycaemic control with metformin monotherapy, the addition of SGLT2i has been found to be more effective in reducing $\mathrm{A} 1 \mathrm{C}$ in patients with T2DM. A metaanalysis of 9 RCTs (each lasting $<1$ year) compared metformin alone with metformin plus SGLT2i. The study reported that a combination therapy was associated with a greater reduction in A1C compared to metformin monotherapy (pooled between-group difference 0.61\%; 95\% CI 0.52-0.71) [61]. Moreover, a systematic review and NMA investigated the efficacy of SGLT2i in patients with T2DM inadequately controlled with metformin monotherapy. The mean difference (MD) of A1C between dual therapies compared to placebo (metformin) 


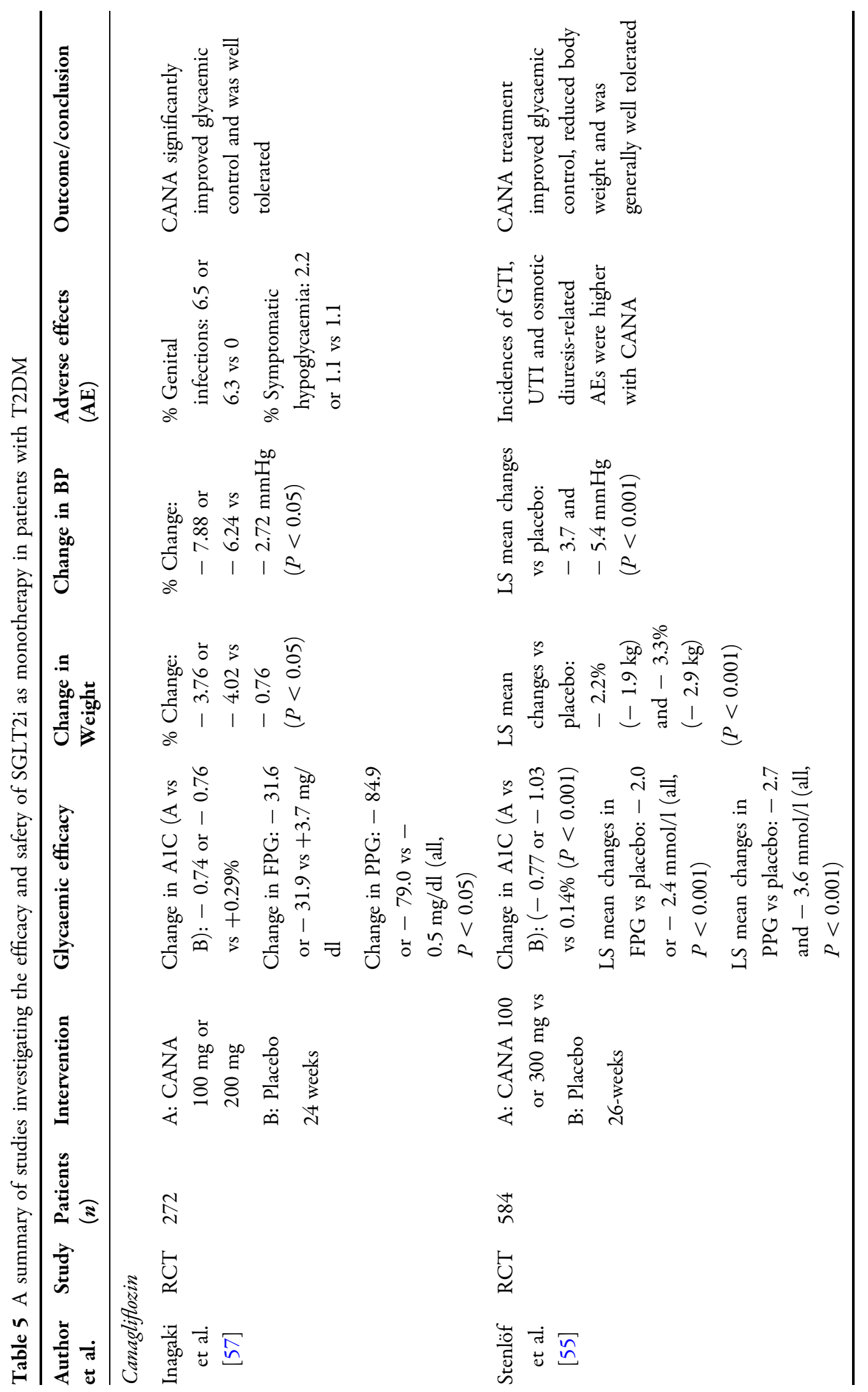




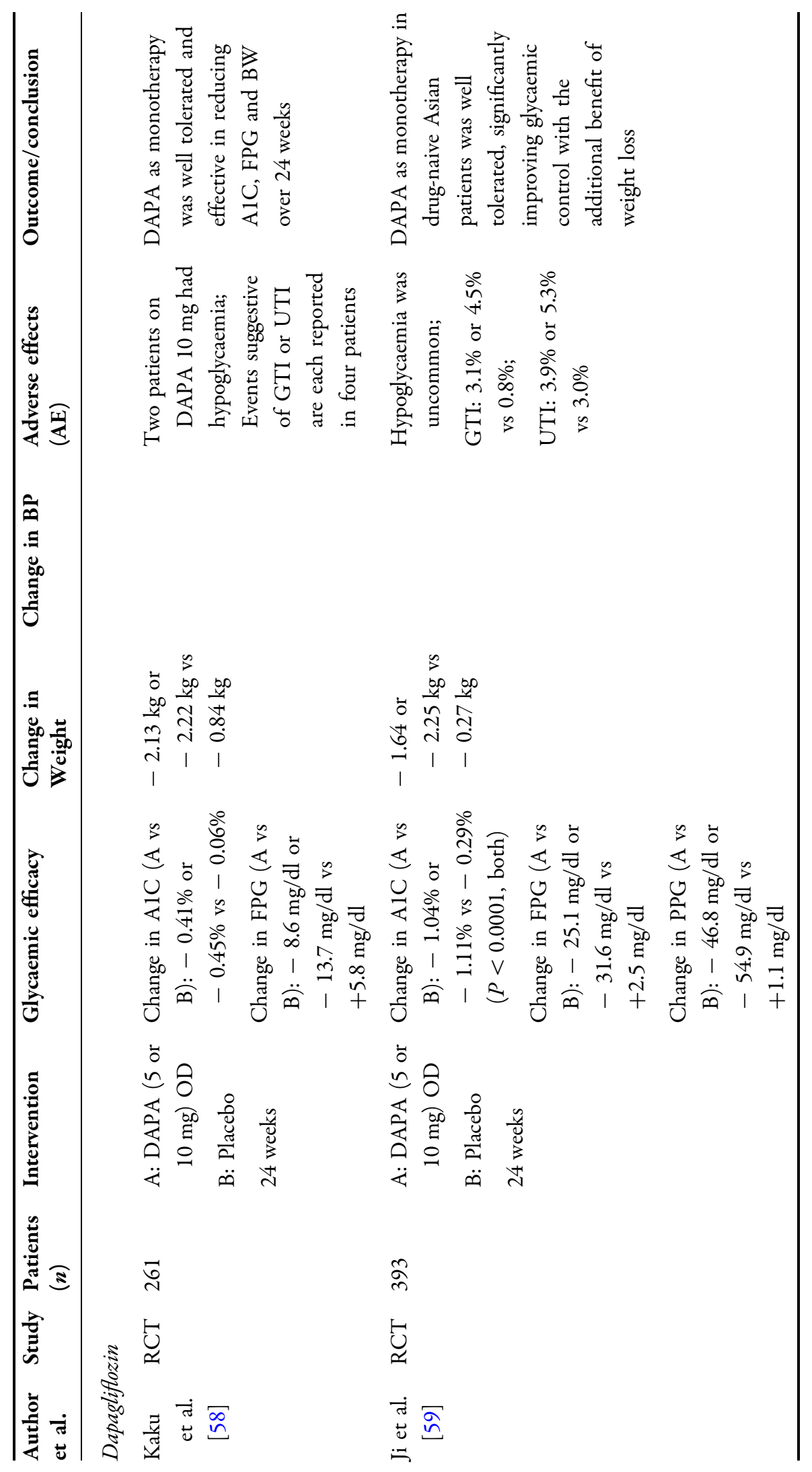




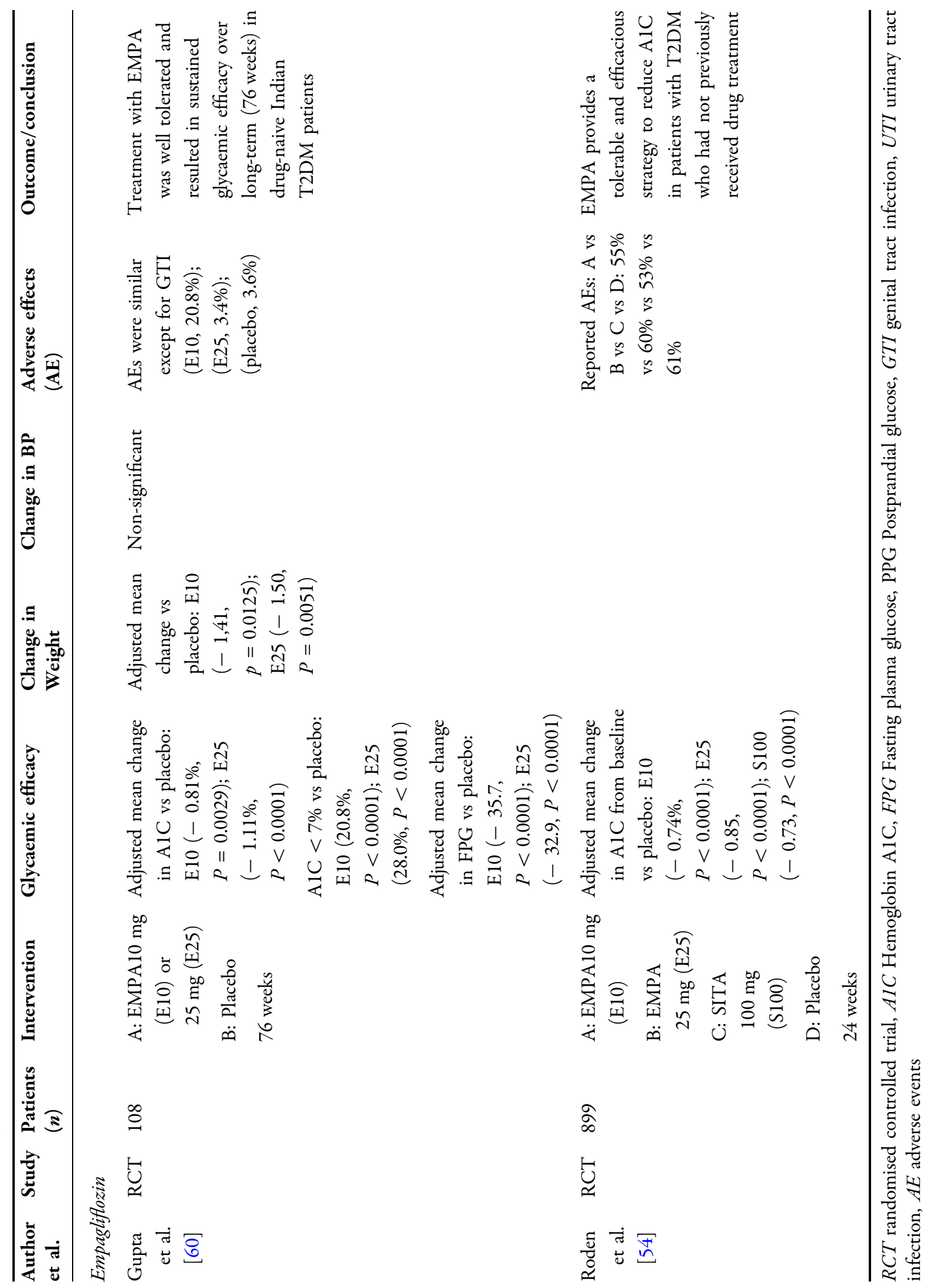


ranged from -0.54 to $-0.77 \%$, and relatively more patients achieved $\mathrm{A} 1 \mathrm{C}<7.0 \%$ with dual therapy compared to placebo (risk ratio [RR], 1.46-2.16) [62]. Similarly, another NMA reported that the addition of SGLT2i was associated with an A1C reduction of $0.48-0.72 \%$ compared to metformin monotherapy [63]. Several RCTs have also reported a meaningful A1C reduction with dual therapy of metformin and SGLT2i compared to metformin monotherapy in patients with T2DM. The glycaemic efficacy of SGLT2 $i$ as a second-line agent investigated in various RCTs is elaborated in Table 6 [64-72].

\section{SGLT2i vs Active Comparator}

A meta-analysis including 6 RCTs compared the efficacy and safety of SGLT2i with non-SGLT2i combinations as an add-on to metformin [73]. The study reported that SGLT2i reduced A1C significantly more than non-SGLT2i (glimepiride/linagliptin/sitagliptin/glipizide) combinations after 52 weeks $(P=0.002)$ and after 104 weeks $(P<0.00001)$. Furthermore, FPG was also significantly reduced $(P<0.00001)$ with SGLT2i compared to non-SGLT2i combinations at 52 and 104 weeks [73]. In a meta-analysis of several RCTs, Bolen et al. reported that in terms of A1C reduction, metformin + SGLT2i was more favoured than metformin + sulfonylureas (pooled between-group difference 0.17\%; 95\% CI $0.14-0.20 \%$, and metformin + DPP4i (pooled between-group difference 0.17\%; 95\% CI $0.08-0.26 \%$ ) [61]. A systematic literature review and Bayesian NMA of RCTs investigated the efficacy of antidiabetic treatments added to metformin. The A1C reduction after 1 year of treatment with SGLT2i was - 0.08\% $(95 \% \mathrm{CI}$, -0.25 to 0.10$)$ relative to DPP $4 \mathrm{i},-0.02 \%(95 \%$ $\mathrm{CI},-0.24$ to 0.21 ) relative to thiazolidinediones, and $0.0 \%$ (95\% CI, -0.16 to 0.16$)$ ] relative to sulphonylureas [74]. Numerous RCTs also favour metformin and SGLT2i combinations over metformin and other antidiabetic agent combinations for efficacy in controlling glycaemic parameters. A list of RCTs comparing the efficacy of metformin and SGLT2i combination versus metformin and other antidiabetic agent combinations is shown in Table 7 [64, 75-79].
Evidence suggests that SGLT2i produce a long-term glycaemic response compared to other antidiabetic agents. In a meta-analysis, SGLT2i, as an add-on to metformin, were associated with a greater reduction in A1C at $\geq 52$ weeks (MD $-0.11 ;-0.20$ to -0.03 ) compared to DPP4i [80]. Similarly, an NMA also reported that A1C reduction with SGLT2i as a second-line agent was high when compared to DPP4i, and that the A1C reduction was at least as large as glucagon-like peptide receptor agonists (GLP-1 RA) at 104 weeks [81]. An extension of an earlier double-blind phase III RCT compared the durability of SGLT2i versus sulfonylureas. At 208 weeks, SGLT2i produced sustained reductions in A1C (MD - 0.30\%, 0.51 to -0.09 ) compared to sulfonylureas; and the A1C coefficient of failure was significantly lower for SGLT2i than for sulfonylureas $(0.19$ vs 0.61 , difference $-0.42 ; P=0.0001$ ) [76]. This confirms the durability of SGLT2i in the reduction of A1C in patients with T2DM compared to other antidiabetic agents.

Emerging evidence also suggests that SGLT2i might be more efficacious in lowering plasma glucose when the A1C value is $>8-8.5 \%$ while DPP4 inhibitors work better when the A1C value is $<8.0 \%[82,83]$.

In short-term real-world settings, SGLT2 $\mathrm{i}$ have produced consistent efficacy and safety effects in an Indian population with T2DM. In a post hoc analysis of 4 double-blind RCTs, SGLT2i were associated with an A1C reduction of $-0.74 \%$ to $-0.88 \%$, and FPG reduction of $-1.0 \mathrm{mmol} / \mathrm{L}$ to $-1.8 \mathrm{mmol} / \mathrm{L}$ [84]. Similarly, a prospective analysis by Sosale et al. reported an A1C reduction of $-1.02 \pm 0.24 \%$, and a retrospective study by Baruah et al. reported a significant $\mathrm{A} 1 \mathrm{C}$ reduction from baseline $(9.0 \%$ at baseline to $6.8 \%$ at follow-up, $P<0.005$ ) with SGLT2i $[85,86]$.

\section{Extra-Glycaemic Benefits}

In addition to glycaemic benefits, SGLT2i have several extra-glycaemic benefits such as body weight reduction, BP reduction, lipid level regulation, CV risk reduction, renoprotective effect, and lowering hypoglycaemic risk. Extra- 
Table 6 A summary of RCTs investigating the efficacy of SGLT2i as an add-on to metformin in patients with T2DM

\begin{tabular}{|c|c|c|c|c|}
\hline $\begin{array}{l}\text { Author } \\
\text { et al. }\end{array}$ & $\begin{array}{l}\text { Patients } \\
(\mathrm{N})\end{array}$ & Intervention & Comparator & Glycaemic efficacy \\
\hline $\begin{array}{l}\text { Lavalle- } \\
\text { González } \\
\text { et al. [64] }\end{array}$ & 918 & $\begin{array}{l}\text { A: CANA } 100 \mathrm{mg} \text { or } \\
300 \mathrm{mg} \text { daily }\end{array}$ & $\begin{array}{l}\text { B: Placebo } \\
26 \text { weeks }\end{array}$ & $\begin{array}{l}\text { A1C: } \downarrow \text { from baseline }(\mathrm{A} \text { vs } \mathrm{B}):-0.79 \text { or }-0.94 \% \\
\quad \text { vs }-0.17 \%(P<0.001) \\
\text { FPG: } \downarrow \text { from baseline }(\mathrm{A} \text { vs } \mathrm{B}):-1.5 \text { or } \\
\quad-2.1 \mathrm{mmol} / \mathrm{l} \text { vs }+0.1 \mathrm{mmol} / \mathrm{l}(P<0.001) \\
\text { PPG: } \downarrow \text { from baseline }(\mathrm{A} \text { vs } \mathrm{B}):-2.7 \text { or } \\
-3.2 \mathrm{mmol} / \mathrm{l} \text { vs }-0.6 \mathrm{mmol} / \mathrm{l}(P<0.001) \\
\text { Achievement of target A1C }<7 \%(\mathrm{~A} \text { vs } \mathrm{B}): 45.5 \text { or } \\
57.8 \% \text { vs } 29.8 \%(P=0.000)\end{array}$ \\
\hline $\begin{array}{l}\text { Qiu et al. } \\
{[65]}\end{array}$ & 279 & $\begin{array}{l}\text { A: CANA } 50 \mathrm{mg} \text { or } \\
150 \mathrm{mg} \mathrm{BID}\end{array}$ & $\begin{array}{l}\text { B: Placebo } \\
18 \text { weeks }\end{array}$ & $\begin{array}{l}\text { A1C: } \downarrow \text { from baseline }(\mathrm{A} \text { vs } \mathrm{B}):-0.45 \text { or }-0.61 \% \\
\quad \text { vs }-0.01 \%(P<0.001) \\
\text { FPG: } \downarrow \text { from baseline }(\mathrm{A} \text { vs } \mathrm{B}):-0.7 \text { or } \\
-1.2 \mathrm{mmol} / \mathrm{l} \text { vs }+0.3 \mathrm{mmol} / 1 \\
\text { Achievement of target } \mathrm{A} 1 \mathrm{C}<7 \%(\mathrm{~A} \text { vs } \mathrm{B}): 47.8 \text { or } \\
57.1 \% \text { vs } 31.5 \%(P<0.05 \text { or } P<0.001 \text { vs } \\
\text { placebo })\end{array}$ \\
\hline Ji et al. [66] & 676 & $\begin{array}{l}\text { A: CANA } 100 \mathrm{mg} \text { or } \\
300 \mathrm{mg} \text { daily }\end{array}$ & $\begin{array}{l}\text { B: Placebo } \\
18 \text { weeks }\end{array}$ & $\begin{array}{l}\text { A1C: } \downarrow \text { from baseline }(\mathrm{A} \text { vs } \mathrm{B}):-0.97 \text { or }-1.06 \% \\
\quad \text { vs }-0.47 \%(P<0.001) \\
\text { FPG: } \downarrow \text { from baseline }(\text { A relative to } \mathrm{B}):-1.0 \text { or } \\
\quad-1.4 \mathrm{mmol} / 1\end{array}$ \\
\hline $\begin{array}{l}\text { Schumm- } \\
\text { Draeger } \\
\text { et al. [67] }\end{array}$ & 400 & $\begin{array}{l}\text { A: DAPA } 2.5 \mathrm{mg} \text { or } 5 \mathrm{mg} \\
\text { BID }\end{array}$ & $\begin{array}{l}\text { B: Placebo } \\
16 \text { weeks }\end{array}$ & $\begin{array}{l}\text { A1C: } \downarrow \text { from baseline }(\mathrm{A} \text { vs } \mathrm{B}):-0.52 \text { or }-0.65 \% \\
\quad \text { vs }-0.30 \%(P=0.0106 \text { or } P<0.0001) \\
\text { FPG: Significantly greater improvements for DAPA } \\
\text { vs placebo } \\
\text { Achievement of target A } 1 \mathrm{C}<7 \% \text { : Significantly } \\
\text { greater improvements for DAPA vs placebo }\end{array}$ \\
\hline $\begin{array}{l}\text { Bailey et al. } \\
\text { [68] }\end{array}$ & 546 & $\begin{array}{l}\text { A: DAPA } 2.5 \mathrm{mg} \text { or } 5 \mathrm{mg} \\
\text { or } 10 \mathrm{mg} \text { daily }\end{array}$ & $\begin{array}{l}\text { B: Placebo } \\
102 \text { weeks }\end{array}$ & $\begin{array}{l}\text { A1C: } \downarrow \text { from baseline }(\mathrm{A} \text { vs } \mathrm{B}):-0.48 \% \\
\quad(P=0.0008) \text { or }-0.58 \%(P<0.0001) \text {, or } \\
\quad-0.78 \%(P<0.0001) \text { vs }+0.02 \% \\
\text { FPG: } \downarrow \text { from baseline }(\mathrm{A} \text { vs } \mathrm{B}):-1.07 \text { or }-1.47 \\
\quad(P=0.0003) \text {, or }-1.36 \mathrm{mmol} / 1(P=0.0012) \text { vs } \\
-0.58 \mathrm{mmol} / 1 \\
\text { Achievement of target A1C }<7 \%(\mathrm{~A} \text { vs } \mathrm{B}): 20.7 \text { or } \\
26.4((P=0.0202) \text { or } 31.5 \%(P=0.0014) \text { vs } \\
15.4 \%\end{array}$ \\
\hline
\end{tabular}


Table 6 continued

\begin{tabular}{|c|c|c|c|c|}
\hline $\begin{array}{l}\text { Author } \\
\text { et al. }\end{array}$ & $\begin{array}{l}\text { Patients } \\
(\mathrm{N})\end{array}$ & Intervention & Comparator & Glycaemic efficacy \\
\hline $\begin{array}{l}\text { Henry et al. } \\
{[69]}\end{array}$ & - & $\begin{array}{l}\text { A: DAPA } 5 \mathrm{mg} \text { or } 10 \mathrm{mg} \\
\text { daily }\end{array}$ & $\begin{array}{l}\text { B: Placebo } \\
24 \text { weeks }\end{array}$ & $\begin{array}{l}\text { A1C: } \downarrow \text { from baseline }(\mathrm{A} \text { vs } \mathrm{B}):-2.05 \text { vs }-1.35 \% \\
\qquad(P<0.0001) \text {; or }-1.98 \% \text { vs }-1.44 \% \\
\quad(P<0.0001) \\
\text { FPG: Combination therapy statistically superior to } \\
\text { monotherapy }(P<0.0001)\end{array}$ \\
\hline $\begin{array}{l}\text { Häring } \\
\text { et al. [70] }\end{array}$ & 637 & $\begin{array}{l}\text { A: EMPA } 10 \mathrm{mg} \text { or } 25 \mathrm{mg} \\
\text { daily }\end{array}$ & $\begin{array}{l}\text { B: Placebo } \\
24 \text { weeks }\end{array}$ & $\begin{array}{l}\text { A1C: } \downarrow \text { from baseline }(\mathrm{A} \text { vs } \mathrm{B}):-0.70 \text { or }-0.77 \% \text { vs } \\
\quad-0.13 \%(P<0.001) \\
\text { FPG: } \downarrow \text { from baseline }(\mathrm{A} \text { vs } \mathrm{B}):-1.11 \text { or } \\
\quad-1.24 \mathrm{mmol} / \mathrm{l} \text { vs }+0.35 \mathrm{mmol} / 1(P<0.001) \\
\text { PPG: } \downarrow \text { from baseline }(\mathrm{A} \text { vs } \mathrm{B}):-2.55 \text { or } \\
\quad-2.47 \mathrm{mmol} / \mathrm{l} \text { vs }+0.33 \mathrm{mmol} / \mathrm{l}(P<0.001) \\
\text { Achievement of target A } 1 \mathrm{C}<7 \%(\mathrm{~A} \text { vs } \mathrm{B}): 37.7 \text { or } \\
38.7 \% \text { vs } 12.5 \%(P<0.001)\end{array}$ \\
\hline $\begin{array}{l}\text { Ross et al. } \\
\qquad[71]\end{array}$ & 983 & $\begin{array}{l}\text { A: EMPA } 12.5 \mathrm{BID} \text { or } \\
25 \mathrm{mg} \text { OD or } 5 \mathrm{mg} \text { BID } \\
\text { or } 10 \mathrm{mg} \mathrm{OD}\end{array}$ & $\begin{array}{l}\text { B: Placebo } \\
16 \text { weeks }\end{array}$ & $\begin{array}{l}\text { A1C: } \downarrow \text { from baseline (E12.5 mg BID vs } 25 \mathrm{mg} \\
\text { daily), }-0.11 \% \text {; and (E5 mg BID vs } 10 \mathrm{mg} \\
\text { daily), }-0.02 \%\end{array}$ \\
\hline $\begin{array}{l}\text { Merker } \\
\text { et al. [72] }\end{array}$ & 463 & $\begin{array}{l}\text { A: EMPA } 10 \mathrm{mg} \text { or } 25 \mathrm{mg} \\
\text { daily }\end{array}$ & $\begin{array}{l}\text { B: Placebo } \\
76 \text { weeks }\end{array}$ & $\begin{array}{l}\text { A1C: } \downarrow \text { from baseline (vs B): }-0.6 \text { or }-0.7 \% \\
\quad(P<0.001)\end{array}$ \\
\hline
\end{tabular}

A1C Hemoglobin A1C, FPG Fasting plasma glucose, PPG Postprandial glucose, $C A N A$ canagliflozin, $D A P A$ dapagliflozin, EMPA empagliflozin

glycaemic benefits associated with SGLT2i are depicted in Fig. 2 [13, 87].

\section{Body Weight Reduction}

Reduction of body weight decreases diabetesrelated complications and improves the patient's QoL and wellbeing. Details regarding the benefits associated with body weight reduction in patients with T2DM are depicted in Fig. 3 [1, 88-91]. A systematic review and metaanalysis of RCTs concluded that a weight loss of $>5 \%$ had beneficial effects on A1C, lipids, and BP in patients with T2DM [91]. A post hoc analysis of the Look AHEAD trial reported that patients with T2DM who lost at least $10 \%$ of body weight during a 1-year period have a $21 \%$ lower risk of fatal and non-fatal CV events (adjusted hazard ratio [AHR] $0.79, P=0.034)$ and a $24 \%$ reduced risk of other CV events (AHR 0.76,
$P=0.003)$ compared with individuals with stable weight or weight gain [92]. Evidence from the Look AHEAD trial also reported that body weight reduction reduced several microvascular complications in T2DM patients [90, 93]. In addition, a reduction of body weight improved glycaemic control, insulin sensitivity, insulin resistance, HOMA IR, and $\beta$-cell function in patients with T2DM $[88,89,94]$. Therefore, weight reduction is inevitable in T2DM patients to reduce mortality and morbidity.

SGLT2i have a significant effect on body weight reduction, which occurs primarily (about two-thirds) due to fat mass loss from the abdomen rather than lean mass [95]. Tosaki et al. investigated $132 \mathrm{~T} 2 \mathrm{DM}$ patients and reported that 6 months of treatment with SGLT2i was associated with a significant reduction of the visceral fat area $(P<0.001)$ and waist 
Table 7 A summary of RCTs investigating the efficacy of SGLT2i compared to non-SGLT2i as an add-on to metformin in patients with T2DM

\begin{tabular}{|c|c|c|c|c|}
\hline Author et al. & $\begin{array}{l}\text { Patients } \\
(\mathrm{N})\end{array}$ & Intervention & Comparator & Glycaemic efficacy \\
\hline $\begin{array}{l}\text { Leiter et al. } \\
\text { [75] }\end{array}$ & 1450 & $\begin{array}{l}\text { A: CANA } 100 \mathrm{mg} \\
\text { or } 300 \mathrm{mg} \text { daily }\end{array}$ & $\begin{array}{l}\text { B: GLIM titrated up } \\
\text { to } 6 \text { or } 8 \mathrm{mg} / \text { daily } \\
104 \text { weeks }\end{array}$ & $\begin{array}{l}\text { A1C: } \downarrow \text { from baseline }(\mathrm{A} \text { vs } \mathrm{B}):-0.65 \text { or } \\
\quad-0.74 \% \text { vs }-0.55 \% \\
\text { FPG: } \downarrow \text { from baseline }(\mathrm{A} \text { vs } \mathrm{B}):-1.1 \text { or } \\
\quad-1.3 \mathrm{mmol} / 1 \text { vs }-0.6 \mathrm{mmol} / 1 \\
\text { Achievement of target } \mathrm{A} 1 \mathrm{C}<7 \% \text { (A vs B): } \\
42.5 \text { or } 50.2 \% \text { vs } 43.9 \%\end{array}$ \\
\hline $\begin{array}{l}\text { Del Prato et al. } \\
\quad[76]\end{array}$ & 814 & $\begin{array}{l}\text { A: DAPA } 2.5,5 \text { or } \\
10 \mathrm{mg}\end{array}$ & $\begin{array}{l}\text { B: GLIP 5, } 10 \text { or } \\
20 \mathrm{mg} \\
208 \text { weeks }\end{array}$ & $\begin{array}{l}\text { A1C: } \downarrow \text { from baseline (A vs B): }-0.10 \text { vs } \\
\quad+0.20 \% \\
\text { FPG: } \downarrow \text { from baseline (A vs B): }-0.7 \text { vs } \\
\quad-0.2 \mathrm{mmol} / 1 \\
\text { A1C coefficient of failure (A vs B): } 0.19 \text { vs } 0.61 \\
\quad(P=0.0001)\end{array}$ \\
\hline $\begin{array}{r}\text { Ridderstråle } \\
\text { et al. [77] }\end{array}$ & 1549 & $\begin{array}{l}\text { A: EMPA } 25 \mathrm{mg} \\
\text { OD }\end{array}$ & $\begin{array}{l}\text { B: GLIM 1-4 mg OD } \\
104 \text { weeks }\end{array}$ & $\begin{array}{l}\text { A1C: } \downarrow \text { from baseline }(\mathrm{A} \text { vs } \mathrm{B}):-0.66 \text { vs } \\
\quad-0.55 \%(P<0.0001 \text { for non-inferiority }) \\
\text { FPG: } \downarrow \text { from baseline }(\text { A relative to } \mathrm{B}):-0.85 \\
\quad \text { or }-0.17 \mathrm{mmol} / \mathrm{l}(P<0.0001)\end{array}$ \\
\hline $\begin{array}{l}\text { Lavalle- } \\
\text { González } \\
\text { et al. [64] }\end{array}$ & 1284 & $\begin{array}{l}\text { A: CANA } 100 \mathrm{mg} \\
\text { or } 300 \mathrm{mg} \text { daily }\end{array}$ & $\begin{array}{l}\text { B: SITA } 100 \mathrm{mg} \text { daily } \\
52 \text { weeks }\end{array}$ & $\begin{array}{l}\text { A1C: } \downarrow \text { from baseline }(\mathrm{A} \text { vs } \mathrm{B}):-0.73 \text { or } \\
\quad-0.88 \% \text { vs }-0.73 \% \\
\text { FPG: } \downarrow \text { from baseline }(\mathrm{A} \text { vs } \mathrm{B}):-1.5 \text { or }-2.0 \\
\text { vs }-1.0 \mathrm{mmol} / \mathrm{l}(P<0.001) \\
\text { Achievement of target } \mathrm{A} 1 \mathrm{C}<7 \%(\mathrm{~A} \text { vs } \mathrm{B}) \text { : } \\
41.4 \text { or } 54.7 \% \text { vs } 50.6 \%\end{array}$ \\
\hline $\begin{array}{l}\text { Rosenstock } \\
\text { et al. [78] }\end{array}$ & 355 & $\begin{array}{l}\text { A: DAPA } 10 \mathrm{mg} \\
\text { daily }\end{array}$ & $\begin{array}{l}\text { B: SAXA } 5 \text { mg daily } \\
102 \text { weeks }\end{array}$ & $\begin{array}{l}\text { A1C: } \downarrow \text { from baseline (A vs B): }-1.20 \% \text { vs } \\
\quad-0.88 \% \\
\text { FPG: } \downarrow \text { from baseline (A vs B): }-32 \mathrm{mg} / \mathrm{dl} \text { vs } \\
\quad-14 \mathrm{mg} / \mathrm{dl} \\
\text { PPG: } \downarrow \text { from baseline (A vs B): }-70 \mathrm{mg} / \mathrm{dl} \text { vs } \\
\quad-36 \mathrm{mg} / \mathrm{dl} \\
\text { Achievement of target A1C }<7 \% \text { (A vs B): } \\
22 \% \text { vs } 18 \%\end{array}$ \\
\hline
\end{tabular}


Table 7 continued

\begin{tabular}{|c|c|c|c|c|}
\hline Author et al. & $\begin{array}{l}\text { Patients } \\
(\mathrm{N})\end{array}$ & Intervention & Comparator & Glycaemic efficacy \\
\hline \multirow[t]{3}{*}{$\begin{array}{l}\text { DeFronzo } \\
\text { et al. [79] }\end{array}$} & 413 & $\begin{array}{l}\text { A: EMPA } 10 \mathrm{mg} \text { or } \\
25 \mathrm{mg} \text { daily }\end{array}$ & $\begin{array}{l}\text { B: LINA } 5 \text { mg daily } \\
52 \text { weeks }\end{array}$ & $\begin{array}{l}\text { A1C: } \downarrow \text { from baseline }(\mathrm{A} \text { vs } \mathrm{B}):-0.66 \text { or } \\
\quad-0.62 \% \text { vs }-0.70 \%\end{array}$ \\
\hline & & & & $\begin{array}{l}\text { FPG: } \downarrow \text { from baseline }(\mathrm{A} \text { vs } \mathrm{B}):-18.8 \mathrm{mg} / \mathrm{dl} \text { or } \\
\quad-20.8 \mathrm{vs}-13.1 \mathrm{mg} / \mathrm{dl}\end{array}$ \\
\hline & & & & $\begin{array}{l}\text { Achievement of target } \mathrm{A} 1 \mathrm{C}<7 \%(\mathrm{~A} \text { vs } \mathrm{B}) \text { : } \\
32.6 \text { or } 28.0 \% \text { vs } 36.1 \%\end{array}$ \\
\hline
\end{tabular}

CANA canagliflozin, GLIM glimepiride, A1C Hemoglobin A1C, FPG Fasting plasma glucose, PPG Postprandial glucose, $D A P A$ dapagliflozin, GLIP glipizide, EMPA empagliflozin, SITA sitagliptin, SAXA saxagliptin, LINA linagliptin



Fig. 2 Extra-glycaemic effects of SGLT2i [13, 87]. BP blood pressure, $H D L-C$ high-density lipoprotein cholesterol, $L D L-C$ low-density lipoprotein cholesterol, IR insulin resistance, $I S$ insulin sensitivity, $\downarrow$ decrease/reduction, $\uparrow$ increase

circumference (WC) $(P<0.001)$ compared to baseline [96]. Similarly, Bolinder et al., in a double-blind RCT, reported that the addition of SGLT2i in patients uncontrolled with metformin reduced body weight by $-4.54 \mathrm{~kg}$, WC by $-5.0 \mathrm{~cm}$ and fat mass by $-2.80 \mathrm{~kg}$ over 102 weeks [97].
A meta-analysis including 6 RCTs ( $\leq 26$ weeks) reported that a combination of SGLT2i and metformin was associated with greater body weight reduction compared to metformin monotherapy (pooled betweengroup difference $-2.0 \mathrm{~kg} ; 95 \% \mathrm{CI}-2.5$ to $-1.5 \mathrm{~kg}$ ) [61]. Similarly, a systematic review and NMA stated that the addition of SGLT2i contributed a greater weight loss (range from -1.63 to $-2.5 \mathrm{~kg}$ ) compared to metformin monotherapy in T2DM patients [62].

Similarly, SGLT2i have been shown to produce a significant weight loss compared to some active comparators when used as a second-line agent. In a systematic review and meta-analysis of RCTs, Li et al. reported that SGLT2i compared to non-SGLT2i (glimepiride/linagliptin/sitagliptin/glipizide), both an add-on to metformin, significantly $(P<0.00001)$ reduced body weight after 52 weeks (MD -3.87 ; -4.94 to -2.80 ) and after 104 weeks (MD - 3.53; - 4.86 to - 2.21) [73]. Moreover, this reduction in body weight was associated with a significant reduction in fat mass (both subcutaneous adipose tissue and visceral adipose tissue) as well as lean mass [73]. Similarly, a meta-analysis of several RCTs found that a combination of metformin and SGLT2i were strongly favoured over metformin and sulfonylurea combination (pooled $\mathrm{MD}-4.7 \mathrm{~kg}$ ), and significantly favoured over metformin and DPP4i combination (range in MD $1.8-3.6 \mathrm{~kg}$ ) in terms of body weight reduction [61]. In addition, low- and high-dose SGLT2i + metformin therapy contributed 


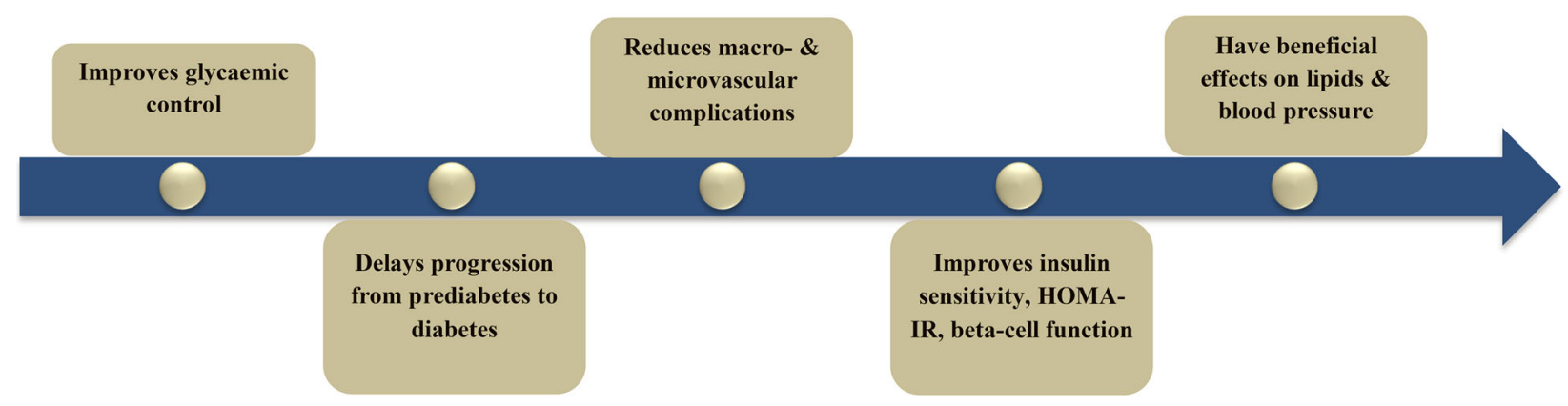

Fig. 3 Possible benefits of weight loss in patients with T2DM [1, 88-91]

$1.8 \mathrm{~kg}(\mathrm{WMD}=-2.2 \mathrm{~kg}, p=0.0000)$, and $2.1 \mathrm{~kg}$ (WMD $=-2.5 \mathrm{~kg}, p=0.0000)$ weight loss, respectively, while DPP4i + metformin resulted in a weight gain of $<0.5 \mathrm{~kg}$ [98]. A recent metaanalysis of 97 RCTs ( $\geq 12$ weeks) reported that SGLT2i were associated with a significant change in body weight from baseline $(-2.04 \mathrm{~kg}, P<0.001)$, and GLP-1 RAs were associated with a comparable change in body weight from baseline $(-1.70 \mathrm{~kg}, P<0.001)$, when used as an add-on therapy [99]. Numerous RCTs also reported a significant weight loss with SGLT2i as a second-line agent (for details see Table 8).

\section{THE INDIAN PHENOTYPE}

Indians have distinct clinical and biochemical deformities, which make them the so-called 'Asian Indian Phenotype'. These abnormalities include higher insulin resistance, elevated abdominal adiposity (i.e., higher visceral fat in spite of lower body mass index [BMI]), lower level of adiponectin and higher level of high sensitive C-reactive protein [100-103]. Moreover, Asian Indians have an increased metabolic risk compared to their counterparts; because of - the existence of high leptin levels [104]; leptin concentration is a significant indicator of body fat $(P<0.0001)$, hip circumference, and fasting insulin [105];

- greater insulin resistance [102, 106, 107];

- higher insulin sensitivity index and lower acute insulin response to glucose [108];

- early loss of $\beta$-cell function [102];

- 'thin-fat Indian concept' or 'sarcopenic obesity' (Asian Indians have thinner limbs [smaller muscle mass] with central obesity, with a higher waist-to-hip ratio and higher subscapular-to-triceps skin fold ratio than their British counterparts, which leads to higher insulin resistance) [109];

- more people suffer from diabetes at a relatively lower BMI compared with those of European descent [110];

- elevated mean A1C level (9.0\%), which is $2.0 \%$ higher than the target suggested by international bodies [109].

SGLT2i could produce multiple benefits in Indian diabetes patients. Table 9 [100-103, 111] shows the list of challenges faced by Indian patients and describes how SGLT2i could overcome the complications.

Evidence advocates that SGLT2i cause weight loss in the Indian population as in the global population. In a post hoc analysis of 4 doubleblind RCTs, SGLT2i were associated with body weight reduction in the Indian population (mean reduction of $-2.5 \%$ and $-3.2 \%$ for CANA $100 \mathrm{mg}$ and $300 \mathrm{mg}$, respectively) [84]. Similarly, a prospective analysis by Sosale et al. reported a weight reduction of $2.64 \pm 1.27 \mathrm{~kg}$ $(P<0.05)$, and a retrospective study by Baruah et al. reported a mean change of weight from baseline $(-2.1 \mathrm{~kg} ;-3.8$ to $-0.32, P<0.05)$ with SGLT2i therapy $[85,86]$.

\section{Blood Pressure Reduction}

It is postulated that certain properties of SGLT2 $\mathrm{i}$ such as osmotic diuresis, mild natriuresis, changes in nitric oxide release, and reductions in arterial stiffness may contribute to BP reduction [61]. A recent systematic review and meta-analysis of RCTs evaluated the efficacy of 
Table 8 A summary of RCTs investigating the extra-glycaemic effect of SGLT2i as an add-on to metformin in patients with T2DM

\begin{tabular}{|c|c|c|c|c|c|}
\hline $\begin{array}{l}\text { Author } \\
\text { et al. }\end{array}$ & $\begin{array}{l}\text { Patients } \\
(n)\end{array}$ & Intervention & Comparator & Change in $\mathrm{BW}$ & Change in SBP \\
\hline $\begin{array}{l}\text { Lavalle- } \\
\text { González } \\
\text { et al. [64] }\end{array}$ & 918 & $\begin{array}{c}\text { A: CANA } 100 \mathrm{mg} \\
\text { or } 300 \mathrm{mg} \text { daily }\end{array}$ & $\begin{array}{l}\text { B: Placebo } \\
26 \text { weeks }\end{array}$ & $\begin{array}{c}-3.3 \text { or }-3.6 \mathrm{~kg} \mathrm{vs} \\
-1.1 \mathrm{~kg}(\text { both } \\
P<0.001)\end{array}$ & $\begin{array}{c}-3.8 \text { or }-5.1 \mathrm{mmHg} \text { vs } \\
+1.5 \mathrm{mmHg} \text { (both } \\
P<0.001)\end{array}$ \\
\hline $\begin{array}{l}\text { Bailey et al. } \\
\text { [68] }\end{array}$ & 546 & $\begin{array}{l}\text { A: DAPA } 2.5 \mathrm{mg} \\
\text { or } 5 \mathrm{mg} \text { or } \\
10 \mathrm{mg} \text { daily }\end{array}$ & $\begin{array}{l}\text { B: Placebo } \\
102 \text { weeks }\end{array}$ & $\begin{array}{l}-1.10 \text { or }-1.70 \text { or } \\
\quad-1.74 \text { vs }+1.36 \mathrm{~kg} \text { (all } \\
\quad P<0.0001)\end{array}$ & $\begin{array}{l}+0.7 \text { or }-1.1 \text { or }-0.3 \mathrm{vs} \\
+1.5 \mathrm{mmHg}\end{array}$ \\
\hline $\begin{array}{l}\text { Haring et al. } \\
{[70]}\end{array}$ & 637 & $\begin{array}{l}\text { A: EMPA } 10 \mathrm{mg} \\
\text { or } 25 \mathrm{mg} \text { daily }\end{array}$ & $\begin{array}{l}\text { B: Placebo } \\
24 \text { weeks }\end{array}$ & $\begin{array}{c}-2.08 \text { or }-2.46 \mathrm{~kg} \mathrm{vs} \\
-0.45 \mathrm{~kg} \text { (both } \\
P<0.001)\end{array}$ & $\begin{array}{c}-4.5 \text { or }-5.2 \mathrm{mmHg} \text { vs } \\
-0.4 \mathrm{mmHg} \text { (both } \\
P<0.001)\end{array}$ \\
\hline $\begin{array}{l}\text { Leiter et al. } \\
\text { [75] }\end{array}$ & 1450 & $\begin{array}{c}\text { A: CANA } 100 \mathrm{mg} \\
\text { or } 300 \mathrm{mg} \text { daily }\end{array}$ & $\begin{array}{l}\text { B: GLIM } \\
\text { titrated up to } \\
6-8 \mathrm{mg} / \text { daily } \\
104 \text { weeks }\end{array}$ & $\begin{array}{l}-3.6 \text { or }-3.6 \mathrm{~kg} \mathrm{vs} \\
\quad+0.8 \mathrm{~kg}\end{array}$ & $\begin{array}{l}-2.0 \text { or }-3.1 \mathrm{mmHg} \text { vs } \\
-1.7 \mathrm{mmHg}\end{array}$ \\
\hline $\begin{array}{l}\text { Del Prato } \\
\text { et al. [76] }\end{array}$ & 814 & $\begin{array}{l}\text { A: DAPA } 2.5,5 \text { or } \\
10 \mathrm{mg}\end{array}$ & $\begin{array}{l}\text { B: GLIP 5, } 10 \text { or } \\
20 \mathrm{mg} \\
208 \text { weeks }\end{array}$ & $-3.65 \mathrm{~kg} \mathrm{vs}+0.73 \mathrm{~kg}$ & $\begin{array}{c}-3.69 \mathrm{mmHg} v \\
-0.02 \mathrm{mmHg}\end{array}$ \\
\hline $\begin{array}{r}\text { Ridderstråle } \\
\text { et al. [77] }\end{array}$ & 1449 & $\begin{array}{l}\text { A: EMPA } 25 \mathrm{mg} \\
\text { daily }\end{array}$ & $\begin{array}{l}\text { B: GLIM } \\
1-4 \text { mg daily } \\
104 \text { weeks }\end{array}$ & $\begin{array}{l}\text { Difference }-4.5 \mathrm{~kg} \\
(P<0.0001)\end{array}$ & $\begin{array}{l}-3.1 \mathrm{mmHg} \text { vs } \\
+2.5 \mathrm{mmHg} \\
(P<0.0001)\end{array}$ \\
\hline $\begin{array}{l}\text { Lavalle- } \\
\text { González } \\
\text { et al. [64] }\end{array}$ & 1284 & $\begin{array}{c}\text { A: CANA } 100 \mathrm{mg} \\
\text { or } 300 \mathrm{mg} \text { daily }\end{array}$ & $\begin{array}{l}\text { B: SITA } 100 \mathrm{mg} \\
\text { daily } \\
52 \text { weeks }\end{array}$ & $\begin{array}{l}-3.3 \text { or }-3.7 \mathrm{~kg} \mathrm{vs} \\
-1.2 \mathrm{~kg}(\text { both } \\
P<0.001)\end{array}$ & $\begin{array}{l}-3.5 \text { or }-4.7 \mathrm{mmHg} \text { vs } \\
-0.7 \mathrm{mmHg} \text { (both } \\
P<0.001)\end{array}$ \\
\hline $\begin{array}{l}\text { Rosenstock } \\
\text { et al. [78] }\end{array}$ & 355 & $\begin{array}{l}\text { A: DAPA } 10 \mathrm{mg} \\
\text { daily }\end{array}$ & $\begin{array}{l}\text { B: SAXA } 5 \mathrm{mg} \\
\text { daily } \\
102 \text { weeks }\end{array}$ & $-2.4 \mathrm{~kg}$ vs $0.0 \mathrm{~kg}$ & $\begin{array}{c}-3.5 \mathrm{mmHg} \text { vs } \\
0.0 \mathrm{mmHg}\end{array}$ \\
\hline $\begin{array}{l}\text { DeFronzo } \\
\text { et al. [79] }\end{array}$ & 413 & $\begin{array}{l}\text { A: EMPA } 10 \mathrm{mg} \\
\text { or } 25 \mathrm{mg} \text { daily }\end{array}$ & $\begin{array}{l}\text { B: LINA } 5 \mathrm{mg} \\
\text { daily } \\
52 \text { weeks }\end{array}$ & $\begin{array}{l}-2.9 \text { or }-2.8 \mathrm{~kg} \mathrm{vs} \\
\quad-0.3 \mathrm{~kg}\end{array}$ & $\begin{array}{l}-3.5 \text { or }-2.8 \mathrm{mmHg} \text { vs } \\
+0.3 \mathrm{mmHg}\end{array}$ \\
\hline
\end{tabular}

$B W$ body weight, $S B P$ systoli BP, CANA canagliflozin, DAPA dapagliflozin, EMPA empagliflozin, GLIM glimepiride, GLIP glipizide, SITA sitagliptin, SAXA saxagliptin, LINA linagliptin

SGLT2i in 24-h ambulatory BP [113]. SGLT2i significantly reduced 24-h ambulatory systolic and diastolic BP by $-3.76 \mathrm{mmHg}(95 \% \mathrm{CI}-$ 4.23 to $\left.-2.34 ; I^{2}=0.99\right)$ and $-1.83 \mathrm{mmHg}$ $\left(95 \%\right.$ CI -2.35 to $\left.-1.31 ; I^{2}=0.76\right)$, respectively [113]. Similarly, several meta-analyses have also advocated that the addition of SGLT2i to metformin was associated with a significant reduction in $\mathrm{BP}$ when compared to metformin monotherapy [61-63].

Compared to other antidiabetic drugs, SGLT2i also provide a significant reduction in 
Table 9 Evolving role of SGLT2i in Indian phenotype with T2DM [100-103, 111]

\begin{tabular}{ll}
\hline Challenges with Indian patients & Relevant SGLT2i features \\
\hline $\begin{array}{l}\text { Higher abdominal adiposity and visceral fat at any given body mass } \\
\text { index }\end{array}$ & $\begin{array}{c}\downarrow \text { Body weight (more visceral fat mass loss than } \\
\text { subcutaneous fat loss) }\end{array}$ \\
$\begin{array}{l}\text { Higher waist circumference and waist to hip ratio } \\
\text { Low level of adipokine and high plasma leptin increases }\end{array}$ & $\downarrow$ Woth triglycerides and leptin \\
concentrations of triglycerides & $\uparrow$ Rate of glucose disposal \\
Low rate of glucose disposal & Improve $\beta$-cell function and $\downarrow$ insulin resistance \\
\hline
\end{tabular}

BP when used as a second-line agent. In an NMA, SGLT2i significantly reduced systolic BP compared to sulfonylurea (range 4.4-5.64 $\mathrm{mmHg}$ ), and DPP4i (range 2.26-5.79 $\mathrm{mmHg}$ ) [63]. In another meta-analysis, the combination of metformin and SGLT2i were favoured in terms of BP reduction compared to metformin and sulfonylurea combination (pooled between-group difference $5.1 \mathrm{mmHg}$; 95\% CI $4.2-6.0 \mathrm{mmHg}$ ), and metformin and DPP4i combination (pooled between-group difference $4.1 \mathrm{mmHg}$; 95\% CI 3.6-4.6 mmHg) [61]. In addition, the durability of BP reduction with SGLT2i is similar to that of its other properties, such as glycaemic control and body weight reduction [76], which may boost its use in patients with T2DM. Moreover, evidence advocates that, unlike GLP1 RAs, SGLT2i do not trigger an increase in heart rate, despite reductions in BP [13]. Numerous RCTs also reported a significant systolic BP reduction with SGLT2i as a second-line agent (for details see Table 8).

\section{Regulation of Lipid Levels}

SGLT2i have been associated with a small increase in high-density lipoprotein cholesterol (HDL-C) as well as low-density lipoprotein cholesterol (LDL-C) and a reduction in triglyceride levels [13, 87]. Meta-analyses of several RCTs reported that treatment with SGLT2i was associated with a small increase in HDL-C level in T2DM patients with no clinically significant changes in LDL-C and triglyceride level $[47,114]$. In a double-blind RCT, SGLT2i treatment in T2DM patients who were uncontrolled with metformin reported an increase in HDL-C and a reduction in triglycerides compared with placebo [115]. Furthermore, SGLT2i compared to DPP4i caused a significant increase in HDL-C and LDL-C levels after 24 weeks [116].

\section{Cardiovascular Risk Reduction}

Cardiovascular disease (CVD) remains the prominent cause of mortality and morbidity in developing countries [117]. The literature advocates that hypertension and diabetes are more important risk factors in younger Indian women than in men; women have a higher prevalence of hypertension and diabetes compared to men [118]. Moreover, abnormalities in lipid metabolism play a vital role in the development of CAD in young Indians [118]. Evidence suggests that SGLT2i provide CV benefits in patients with T2DM $[119,120]$. Various possible routes that might influence the CV benefits of SGLT2i are depicted in Fig. 4 [87]. A systematic review and meta-analysis including several RCTs reported that SGLT2i reduced the risk of major adverse CV events (MACE) (RR 0.84; $P=0.006$ ), CV death (RR 0.63; $P<0.0001$ ), heart failure (RR 0.65; $P=0.002$ ), and death from any cause (RR 0.71; $P<0.0001)$, compared to a control group. However, an adverse effect on non-fatal stroke (RR $1.30 ; P=0.049$ ) was observed. Moreover, these CV benefits of SGLT2i are a class effect rather than an individual effect [120].

Similarly, an NMA compared the effectiveness of SGLT2i against other oral antidiabetic drugs (OADs) (metformin, sulfonylureas, thiazolidinedione, and DPP4i) in preventing CV 


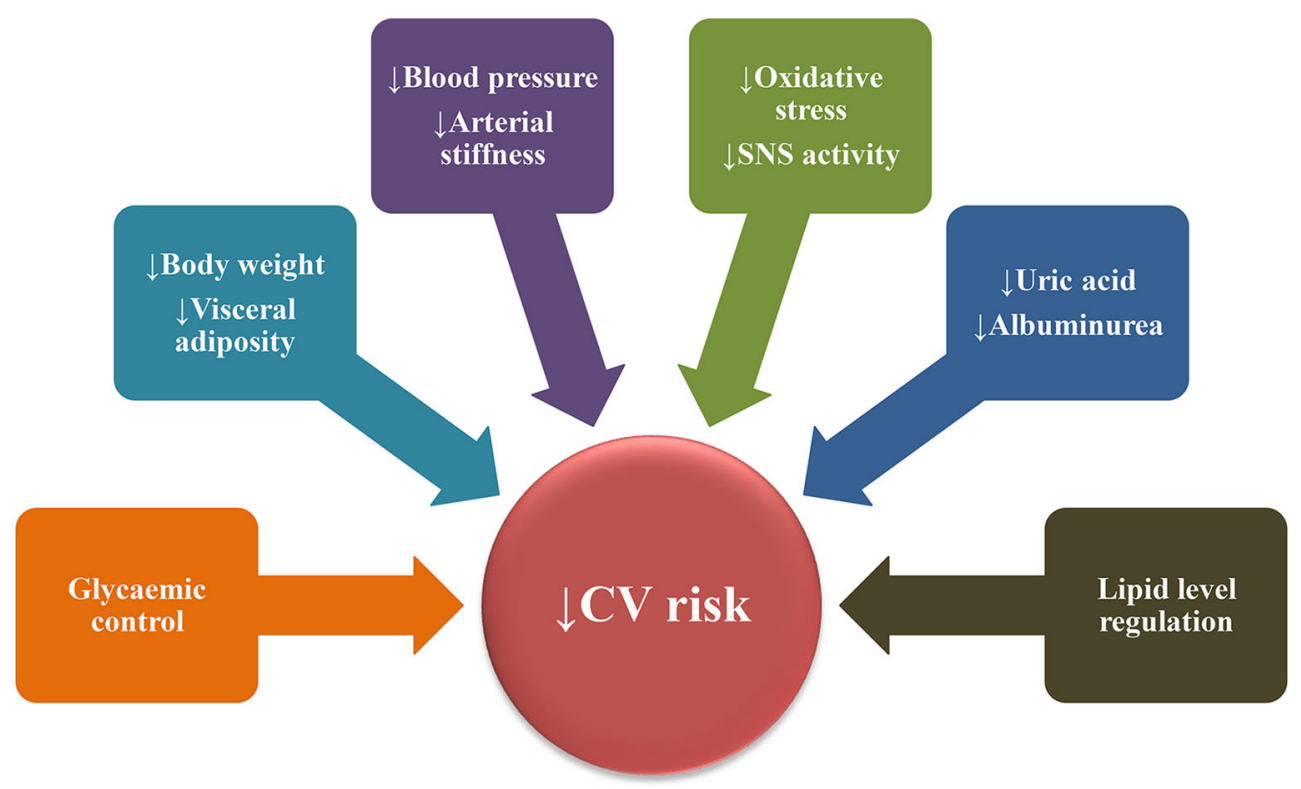

Fig. 4 Possible pathways that may impact CV benefits of SGLT2i [87]. CV cardiovascular, SNS somatic nervous system, $\downarrow$ decrease/reduction. Reproduced with permission from Inzucchi, Zinman, Wanner, et al. SGLT-2 inhibitors

mortality and morbidity [119]. The relative risk for all-cause mortality, CV mortality, acute coronary syndrome, and myocardial infarction (MI) (only against DPP4i and placebo) were reported to be low for SGLT2i compared to all other OADs [119]. Moreover, another metaanalysis reported that SGLT2i along with their multifactorial benefits were associated with no increased risk for MACE in various subgroup populations (e.g., degree of CV risk, any other risk, and hypoglycaemia) [121]. In line with the evidence, several pooled analyses of RCTs [122, 123], CANVAS trial [124], and EMPA-REG OUTCOME trial [125] advocate that SGLT2i are associated with a lower incidence of CV mortality and morbidity compared to placebo in high-risk CV patients. Moreover, the results of the major ongoing Dapagliflozin Effect on CardiovascuLAR Events (DECLARE-TIMI 58) trial will shed light on the long-term CV effectiveness of SGLT2i in T2DM patients [126]. Thus, SGLT2i may have a better impact on women with CVD as more women are prone to heart disease in India.

In addition, several instances of real-world evidence including the CVD-REAL study [127], and cardiovascular risk: Proposed pathways and review of ongoing outcome trials. Diabetes and Vascular Disease Research. 2015; 12:90-100

UK THIN database study [128], and Swedish national registries [129] have also reported that treatment with SGLT2i was associated with a lower risk of $\mathrm{CV}$ event, mortality and morbidity compared with other glucose-lowering agents in T2DM patients. The CVD-REAL study included 309,056 patients from six countries (US, Norway, Denmark, Sweden, Germany and the UK) who were newly initiated on either SGLT2i or other antidiabetic drugs. Compared to other antidiabetic drugs, SGLT2i were associated with lower rates of heart failure hospitalization (HHF) (hazard ratio [HR] 0.61; 95\% CI $0.51-0.73 ; P<0.001$ ); death (HR $0.49 ; 95 \%$ CI $0.41-0.57 ; P<0.001$ ), and HHF or death (HR $0.54 ; 95 \%$ CI $0.48-0.60, P<0.001$ ) with no significant heterogeneity by country [127].

\section{Reno-Protective Effect}

Like other benefits, SGLT2i also contribute a renoprotective effect in patients with T2DM. SGLT2i acutely reduced estimated glomerular filtration rate (eGFR), followed by progressive recovery and stabilisation of renal function [130]. In recently published RCTs (CANVAS, 
EMPA-REG OUTCOME), SGLT2i were associated with slower progression of kidney disease, reduced progression of albuminuria, and reduction of eGFR with lower rates of clinically relevant renal adverse events in high-risk patients [124, 131]. Moreover, a pooled analysis of 12 RCTs reported that SGLT2i were not associated with an increased risk of acute renal toxicity or deterioration of renal function in T2DM patients with normal or mildly impaired renal function [132]. Furthermore, compared to glimepiride, SGLT2i reduced the progression of renal disease over 104 weeks, and may confer renoprotective effects independently of their glycaemic effects in patients with T2DM [133].

\section{MISCELLANEOUS EFFECTS}

\section{Improved Insulin Sensitivity and B-Cell Function}

Evidence suggests that SGLT2i improve insulin sensitivity and $\beta$-cell function in the setting of A1C and weight reduction in patients with T2DM $[112,134,135]$. SGLT2i may be beneficial in insulin-resistant patients due to their proven benefits in both improving insulin sensitivity and weight reduction. In a placebo-controlled RCT, $\quad$ SGLT2i significantly $\quad(P=0.0059)$

\section{Recommendation: Dual Therapy}

- In T2DM patients with unmet needs of glycaemic control with metformin monotherapy, SGLT2i are a preferred option as a second-line agent (Grade A, EL 1)

- SGLT2i as monotherapy and as an add-on to metformin effectively reduce A1C, FPG, body weight and BP in patients with T2DM (Grade A, EL 1)

- In patients with T2DM, SGLT2i provide superior long-term glycaemic efficacy compared to DPP4i and sulfonylureas (Grade A, EL 1)

- Compared to sulfonylureas, SGLT2i as a second-line agent, are associated with non-inferior glycaemic control with a significant reduction in body weight, $\mathrm{BP}$ and rates of hypoglycaemia (Grade A, EL 1)

- When used as a second-line agent after metformin, SGLT2i are more effective in terms of glycaemic control, body weight, and BP reduction than DP44 inhibitors (Grade A, EL 1)

- SGLT2i significantly reduce the risk of CV morbidity and mortality (Grade A, EL 1)

- SGLT2i are associated with renoprotective effects such as slower progression to kidney disease and slower progression of albuminuria, and a reduction of eGFR in patients with T2DM (Grade A, EL 1) 
improved insulin sensitivity versus placebo [134] and in another RCT [136] they significantly reduced insulin resistance $(p<0.001)$ in T2DM patients.

\section{Improves Serum Magnesium}

A post hoc analysis of 4 RCTs reported that SGLT2i control the level of serum magnesium in hypomagnesaemia patients with T2DM, which may subsequently improve the cardiometabolic outcome [142].

\section{Recommendation: Miscellaneous Effects}

- SGLT2i improve insulin sensitivity and $\beta$-cell function and reduce insulin resistance; therefore, they are recommended in insulin-resistant T2DM patients (Grade A, EL 2)

- When combined with insulin, SGLT2i may decrease the cost of insulin treatment by reducing the daily insulin dose requirements (Grade B, EL 3)

- Treatment with SGLT2i may reduce the level of uric acid and decrease albuminuria; thus, they might decrease diabetes complications in patients with T2DM (Grade B, EL 3)

\section{Reduction of Daily Insulin Dose and Cost of Treatment}

In patients with unmet needs of glycaemic control with maximum doses of OADs and insulin, the addition of SGLT2i reduces daily insulin dose requirement and therefore the cost of insulin therapy [137]. Moreover, a UK healthcare system perspective analysis confirmed that SGLT2i + metformin are more costeffective than DPP4i + metformin [138].

\section{Reduction of Uric Acid Level}

Many patients with T2DM have high serum uric acid levels that might damage the kidney and cause several microvascular complications [139]. Evidence suggests that SGLT2i significantly reduced the levels of uric acid in the plasma $[140,141]$. They may also inhibit reabsorption of sodium coupled-uric acid in the PCT, resulting in increased uric acid elimination [13].

\section{SAFETY AND TOLERABILITY}

\section{Hypoglycaemia}

Hypoglycaemia is a major cause of concern with some antidiabetic agents; however, pertaining to their insulin-independent mechanism of action, SGLT2i produce less hypoglycaemia than other antidiabetic agents $[13,25]$. Nonetheless, when SGLT2i are used concomitantly with insulin or insulin secretagogues, the risk of hypoglycaemia increases, and close monitoring of the patient is required [143]. Li et al., in a meta-analysis, found that SGLT2i compared to non-SGLT2i were associated with a significantly lower incidence of hypoglycaemic events when used as an add-on to metformin (OR 0.27; $P=0.02$ ) [73]. SGLT2i were associated with a lower incidence of mild or moderate hypoglycaemia compared to sulfonylureas when used after metformin monotherapy (5\% vs $34 \%)$ [144]; and a similar incidence of hypoglycaemia was documented when compared to DPP4i (4.2\% vs $4.7 \%)$ [64]. 


\section{UTI and GTI}

Increased urinary glucose levels due to the use of SGLT2i results in glycosuria. This subsequently increases the risk of GTIs (balanitis and balanoposthitis in men and vulvovaginitis in women) and to a relatively lesser extent UTIs [13]. In a metaanalysis of RCTs, the incidence of suspected or confirmed GTIs was reported to be significantly $(P<0.00001)$ higher with SGLT2i (OR 6.41 [95\% CI 3.58, 11.45] for men and 5.12 [95\% CI 3.48, 7.54] for women) compared to non-SGLT2i agents, both used as an add-on to metformin [73]. However, a meta-analysis of several RCTs found inconsistent results regarding the incidence of UTI between SGLT2i and DPP4i, and between SGLT2i and sulfonylureas, when all added to metformin [13]. Similar results were also reported in a post hoc analysis conducted in Indian T2DM patients [9]. Nevertheless, the incidence of GTIs and UTIs is more common in females than in males, and can be corrected through standard treatment. The South Asian Federation of Endocrine Societies (SAFES) consensus statement advocates that perineal hygiene should be maintained to prevent GTIs and, after 3 months of GTI-free status, patients with T2DM can be prescribed with SGLT2i along with prophylactic antifungal coverage. However, SGLT2i should be avoided in the case of a previous history of upper UTIs, complicated GTIs, or refractory or resistant GTIs [13].

\section{Volume Depletion}

Glycosuria caused by SGLT2i triggers volume depletion by eliminating more fluid from the body through the process of osmotic diuresis [13, 145]. The adverse events associated with volume depletion are BP reduction, dehydration, postural dizziness, orthostatic hypotension, orthostatic intolerance, syncope, and reduction in urine output. A meta-analysis of several RCTs stated that the difference in volume depletion between SGLT2 $i$ + metformin and DPP4 $i$ metformin was unclear. However, the study found a small difference between sulfonylureas + metformin and SGLT2i + metformin (pooled OR 1.0; 95\% CI 0.6-1.7) [61]. Moreover, volume depletion-related events were reported to be higher with SGLT2i in different RCTs when compared to sulfonylureas (3\% vs < 1\%) [144], and DPP4i (3.0\% vs 0.5\%) [64]. In addition, a post hoc analysis of phase III RCTs also reported a similar incidence of volume depletion-related adverse events with SGLT2i in an Indian population vis-à-vis the overall population [84]. Hence, before prescribing SGLT2i, analysis of volume status and thorough monitoring of volume depletion-related adverse events is highly obligatory in T2DM patients.

\section{Bone Fractures and Osteoporosis}

The risk of bone fracture is increased in people with diabetes compared to their non-diabetic counterparts [146]. Patients with type $1 \mathrm{DM}$ are at a higher risk of osteoporosis, and the risk of hip fracture is generally increased in patients with T2DM [1]. SGLT2i should be used with caution in patients with T2DM who have a high fracture risk [1]. Due to their osmotic diuresis effect, SGLT2i cause volume depletion which subsequently disturbs the electrolyte (serum calcium and phosphate) concentration in the body, and may show a harmful effect on bone health [147]. Moreover, SGLT2i elevate serum phosphate and subsequently enhance the secretion of a parathyroid hormone that may increase bone resorption and the risk of bone fractures [148]. In addition, hyponatraemia caused by SGLT2i might increase osteoporosis and fracture risk [147]. A pooled analysis of 9 RCTs (including the CANVAS trial; $n=4,327$ ) reported that only patients from the CANVAS trial who were continuing CANA had shown a higher risk of fracture when compared to non-CANA patients (4\% vs 2.6\%) [149]. Moreover, EMPA also revealed few fracture incidents in CKD patients with T2DM in a double-bind RCT [150]. However, an international multi-centre, parallel-group, double-blind RCT reported that DAPA had no effect on markers of bone formation and resorption or bone mineral density in T2DM patients [151]. Similarly, a recent meta-analysis of 20 RCTs $(n=8,286)$ revealed that there was no increased risk of bone fracture with SGLT2i treatment compared to placebo in patients with T2DM (SGLT2i vs placebo; pooled risk ratio $0.67,95 \% \mathrm{CI}$ 0.42-1.07) [152]. Nonetheless, SGLT2i should be used cautiously in older patients, and in those 
with a prior history/risk of CVD, with lower baseline eGFR and taking more diuretics at baseline [149].

\section{Peripheral Vascular Disease/Toe Amputation}

The literature suggests that SGLT2i are associated with improvement in CV prognosis in high CV-risk patients with T2DM [153]. However, recent evidence reported that SGLT2i (CANA) was associated with an unexpectedly increased risk of amputation in patients with T2DM [124]. Moreover, the underlying mechanisms that lead to amputation and whether the risk of ampu- tation is particular to SGLT2i remain unclear [153]. The risk of amputation nearly doubled in patients on CANA compared to placebo in participants in the CANVAS trial (6.3 vs 3.4 participants per 1,000 patient-years, corresponding to an HR of $1.97 ; 95 \%$ CI $1.41-2.75$ ) with T2DM and a high $\mathrm{CV}$ risk; $71 \%$ of amputations were primarily at the level of the toe or metatarsal [124]. However, a pooled analysis from 15 RCTs (phase I-III) including the EMPA-REG OUTCOME trial reported no difference in the incidence of amputation in EMPA and placebotreated T2DM patients (both 1.1\%) [154]. Data regarding DAPA on peripheral vascular disease are limited.

\section{Recommendation: Safety}

- Hypoglycaemia risk in patients with T2DM is less with SGLT2i when compared to insulin secretagogues and insulin. Patients taking a combination of SGLT2 $i$ and insulin or insulin secretagogues should be closely monitored (Grade A, EL1)

- SGLT2i are associated with a higher rate of GTIs than other antidiabetic drugs; however, differences in the incidence of UTIs between SGLT2i and other antidiabetic drugs are inconsistently reported (Grade A, EL1)

- Compared to other antidiabetic drugs, SGLT2i are associated with volume depletion- or osmotic diuresis-related adverse events (Grade A, EL1)

- There is insufficient evidence to suggest causality between SGLT2i and an increased risk of bone fracture and osteoporosis in patients with T2DM. Treatment should be individualised in high-risk patients (older patients, with a prior history/risk of CVD) (Grade A, EL1)

- SGLT2i (CANA) are associated with a higher risk of peripheral vascular disease/amputation (Grade A, EL1) 


\section{CONTRAINDICATIONS/WHEN NOT TO USE}

The labelling for SGLT2i includes some warnings or precautions. These include genital mycotic infections, hypoglycaemia (when used with insulin or insulin secretagogues), hyperkalaemia, hypersensitivity reactions, hypotension, impaired renal function, increased LDL-C, UTIs, etc. [143]. SGLT2i are contraindicated in patients with eGFR $<45 \mathrm{~mL} / \mathrm{min} / 1.73 \mathrm{~m}^{2}$, extreme insulinopenic or type 1 diabetes, patients on a fluid/carbohydrate restricted diet, or patients with decompensated medical/surgical illness, pregnant and lactating women and in children [13]. management of T2DM. SGLT2i improve all glycaemic parameters (A1C, FPG, and PPG), and have additional benefits like body weight and $\mathrm{BP}$ reduction, and lipid level regulation. Apart from this, they are also associated with a reduction in CV and renal risk. However, GTIs, DKA and to a lesser extent UTIs are some of the concerns with SGLT2i which can be managed with appropriate patient counselling and treatment individualisation. Taken together, SGLT2i are an attractive option for the management of T2DM patients in the Indian scenario after initial metformin monotherapy failure. Moreover, they can be specifically preferred if body weight and $\mathrm{BP}$ reduction and improving insulin sensi-

\section{Recommendation: Contradictions/When NOT to use}

- SGLT2i are contraindicated in patients with eGFR $<45 \mathrm{~mL} / \mathrm{min} / 1.73 \mathrm{~m}^{2}$, extreme insulinopenic or type 1 diabetes, on a fluid/carbohydrate restricted diet, or with decompensated medical/surgical illness, pregnancy, lactation and in children (Grade A, EL1)

\section{CONCLUSION}

SGLT2i appear to be generally well tolerated and can be safely used as monotherapy or in combination with other OADs and insulin in the tivity are the part of the primary treatment concern.

\section{Recommendation: Indian Phenotype}

- SGLT2i are emerging agents that can provide multiple benefits in Indian diabetes patients (Grade B, EL 3)

- The weight reduction associated with SGLT2i is due to loss of fat mass mainly from the abdomen rather than lean mass (Grade A, EL 2)

- The benefits associated with SGLT2i such as improvement of $\beta$-cell function and reduction of insulin resistance may be more useful in Indian diabetes patients (Grade A, EL 2) 


\section{ACKNOWLEDGEMENTS}

The authors thank AstraZeneca Pharma India Ltd for supporting the conduct of the consensus meeting and providing medical writing assistance in the development of this manuscript.

Funding. The preparation of this consensus statement and funding of the journal's article processing charges was supported by AstraZeneca Pharma India Limited. All authors had full access to all of the data in this study and take complete responsibility for the integrity of the data and accuracy of the data analysis.

Medical Writing Assistance. Medical writing assistance was provided by Syam K Yelamanchi (Jeevan Scientific Technology Limited, Hyderabad.) This was funded by AstraZeneca Pharma India Ltd.

Authorship. All named authors meet the International Committee of Medical Journal Editors (ICMJE) criteria for authorship for this article, take responsibility for the integrity of the work as a whole, and have given their approval for this version to be published.

Expert Group Committee. The authors thank the following members of the expert group committee for their comments and suggestions during the drafting of this consensus statement: Dr. A Bhandari, Dr. AK Ojha, Dr. Amitava Ray, Dr. Amit Dey, Dr. Aniruddha Dey, Dr. Debasis Ghosh, Dr. Debasis Sarkar, Dr. Dibyendu Bhattacharya, Dr. Gurudas Basu, Dr. KK Barman, Dr. MK Mukhopadhyay, Dr. ML Bhansali, Dr. Nadim Akhtar Khan, Dr. Nirmalya Chakrabarty, Dr. Paramartha Bhattacharya, Dr. PK Bhattacharya, Dr. PS Mandal, Dr. Rahul Bhattacharya, Dr. Rangana Chakrabarty, Dr. Saikat Bhawal, Dr. Sampat Jain, Dr. Satish Sutradhar, Dr. Sayak Roy, Dr. Sayan Chattoraj, Dr. Shahnowaj Majumdar, Dr. Soumyabrata Roychowdhury, Dr. Subhas Ch. Saha, Dr. Suddhwasatwa Ghosh, Dr. Supratik Bhattacharyya and Dr. Tapas Chatterjee.

Disclosures. Awadhesh Kumar Singh, Ambika Gopalakrishnan Unnikrishnan, Abdul
Hamid Zargar, Ajay Kumar, Ashok Kumar Das, Banshi Saboo, Binayak Sinha, Kalyan Kumar Gangopadhyay, Pradeep G Talwalkar, Samit Ghosal, Shashank Joshi, Surendra Kumar Sharma, Usha Sriram and Viswanathan Mohan declare that they have no conflict of interest. Sanjay Kalra is a member of the journal's Editorial Board but otherwise has no other conflict of interest.

Compliance with Ethics Guidelines. This article is based on previously conducted studies and does not contain any studies with human participants or animals performed by any of the authors.

Open Access. This article is distributed under the terms of the Creative Commons Attribution-NonCommercial 4.0 International License (http://creativecommons.org/licenses/ by-nc/4.0/), which permits any noncommercial use, distribution, and reproduction in any medium, provided you give appropriate credit to the original author(s) and the source, provide a link to the Creative Commons license, and indicate if changes were made.

\section{REFERENCES}

1. American Diabetes Association. Standards of medical care in diabetes 2018. Diabetes Care. 2018;41(Supplement 1):S1-159.

2. International Diabetes Federation. The International Federation (IDF) Diabetes Atlas, 8th Edition. 2017. http://www.diabetesatlas.org/resources/2017atlas.html. Accessed 20 Feb 2018.

3. IDF diabetes atlas - 8th edition 2017, Across the globe. http://www.diabetesatlas.org/across-theglobe.html. Accessed 20 Feb 2018.

4. Akhtar SN, Dhillon P. Prevalence of diagnosed diabetes and associated risk factors: evidence from the large-scale surveys in India. J Soc Health Diabetes. 2017;5(1):28.

5. Global Report on Diabetes - World Health Organization; 2016. http://apps.who.int/iris/bitstream/ 10665/204871/1/9789241565257_eng.pdf. Accessed 27 Aug 2018. 
6. Tripathy JP, Thakur JS, Jeet G, Chawla S, et al. Prevalence and risk factors of diabetes in a large community-based study in North India: results from a STEPS survey in Punjab, India. Diabetol Metab Syndr. 2017;9(1):8.

7. Gakidou E, Mallinger L, Abbott-Klafter J, et al. Management of diabetes and associated cardiovascular risk factors in seven countries: a comparison of data from national health examination surveys. Bull World Health Organ. 2011;89(3):172-83.

8. de Pablos-Velasco P, Parhofer KG, Bradley C, et al. Current level of glycaemic control and its associated factors in patients with type 2 diabetes across Europe: data from the PANORAMA study. Clin Endocrinol. 2014;80(1):47-56.

9. Kumar KH, Modi KD. A1c, blood pressure and cholesterol goal achievement in patients of Type 2 diabetes. Med J DY Patil Univ. 2016;9(2):195.

10. Low Wang CC, Hess CN, Hiatt WR, Goldfine AB. Clinical update: cardiovascular disease in diabetes mellitus: atherosclerotic cardiovascular disease and heart failure in type 2 diabetes mellitus - mechanisms, management, and clinical considerations. Circulation. 2016;133(24):2459-502.

11. Martín-Timón I, Sevillano-Collantes C, SeguraGalindo A, Del Cañizo-Gómez FJ. Type 2 diabetes and cardiovascular disease: have all risk factors the same strength? World J Diabetes. 2014;5(4):444-70 PubMed PMID: 25126392.

12. Handelsman Y, Bloomgarden ZT, Grunberger G, et al. American Association of Clinical Endocrinologists and American College of Endocrinology clinical practice guidelines for developing a diabetes mellitus comprehensive care plan - 2015. Endocr Pract. 2015;21(s1):1-87.

13. Kalra S, Ghosh S, Aamir AH, et al. Safe and pragmatic use of sodium-glucose co-transporter 2 inhibitors in type 2 diabetes mellitus: South Asian Federation of Endocrine Societies consensus statement. Indian J Endocrinol Metab. 2017;21(1):210.

14. Ehrenkranz JR, Lewis NG, Ronald Kahn C, Roth J. Phlorizin: a review. Diabetes Metab Res Rev. 2005;21(1):31-8.

15. Nauck MA. Update on developments with SGLT2 inhibitors in the management of type 2 diabetes. Drug Des Devel Ther. 2014;8:1335.

16. Pharmaceuticals and Medical Devices Agency, Japan; 2013. http://www.pmda.go.jp/english/ index.html. Accessed 15 Feb 2018.
17. Sarnoski-Brocavich S, Hilas O. Canagliflozin (invokana), a novel oral agent for type-2 diabetes. Pharm Ther. 2013;38(11):656.

18. Kasichayanula S, Liu X, LaCreta F, Griffen SC, Boulton DW. Clinical pharmacokinetics and pharmacodynamics of dapagliflozin, a selective inhibitor of sodium-glucose co-transporter type 2. Clin Pharmacokinet. 2014;53(1):17-27.

19. Ndefo UA, Anidiobi NO, Basheer E, Eaton AT. Empagliflozin (Jardiance): a novel SGLT2 inhibitor for the treatment of type- 2 diabetes. Pharm Ther. 2015;40(6):364.

20. AstraZeneca Pharmaceuticals LP. Prescribing information (08/2016): FARXIGA ${ }^{\circledR} \quad$ (dapagliflozin) tablets, for oral use. https://www.accessdata.fda. gov/drugsatfda_docs/label/2017/202293s011lbl. pdf. Accessed 29 Aug 2018.

21. US Food and Drug Administration. JARDIANCE (empagliflozin) tablets, for oral use: highlights of prescribing information. https://www.accessdata. fda.gov/drugsatfda_docs/label/2016/204629s008lbl. pdf.

22. US Food and Drug Administration. INVOKANA (canagliflozin) tablets, for oral use: highlights of prescribing information. https://www.accessdata. fda.gov/drugsatfda_docs/label/2016/204042s011lbl. pdf. Accessed 29 Aug 2018.

23. Gerich JE. Role of the kidney in normal glucose homeostasis and in the hyperglycaemia of diabetes mellitus: therapeutic implications. Diabet Med. 2010;27(2):136-42.

24. Hediger MA, Rhoads DB. Molecular physiology of sodium-glucose cotransporters. Physiol Rev. 1994;74(4):993-1026.

25. Kumar KP, Ghosh S, Canovatchel W, Garodia N, Rajashekar S. A review of clinical efficacy and safety of canagliflozin $300 \mathrm{mg}$ in the management of patients with type 2 diabetes mellitus. Indian J Endocrinol Metab. 2017;21(1):196.

26. Rajeev SP, Cuthbertson DJ, Wilding JP. Energy balance and metabolic changes with sodium-glucose co-transporter 2 inhibition. Diabetes Obes Metab. 2016;18(2):125-34.

27. Ferrannini G, Hach T, Crowe S, Sanghvi A, Hall KD, Ferrannini E. Energy balance after sodium-glucose cotransporter 2 inhibition. Diabetes Care. 2015;38(9):1730-5.

28. Katz PM, Leiter LA. The role of the kidney and SGLT2 inhibitors in type 2 diabetes. Can J Diabetes. 2015;31(39):S167-75. 
29. Ferrannini E, Muscelli E, Frascerra S, et al. Metabolic response to sodium-glucose cotransporter 2 inhibition in type 2 diabetic patients. J Clin Invest. 2014;124(2):499.

30. Kalra S. Sodium glucose co-transporter-2 (SGLT2) inhibitors: a review of their basic and clinical pharmacology. Diabetes Ther. 2014;5(2):355-66.

31. Chaudhury A, Duvoor C, Dendi VS, et al. Clinical review of antidiabetic drugs: implications for type 2 diabetes mellitus management. Front Endocrinol. 2017;8(6):1-12.

32. Wilding JP, Rajeev SP, DeFronzo RA. Positioning SGLT2 inhibitors/incretin-based therapies in the treatment algorithm. Diabetes Care. 2016;39(Supplement 2):S154-64.

33. Qaseem A, Humphrey LL, Sweet DE, Starkey M, Shekelle P. Oral pharmacologic treatment of type 2 diabetes mellitus: a clinical practice guideline from the American College of Physicians. Ann Intern Med. 2012;156(3):218-31.

34. Type 2 diabetes in adults: management. NICE guidelines 2017. https://www.nice.org.uk/ guidance/ng28. Accessed 31 Aug 2018.

35. International Diabetes Federation 2017. IDF Clinical Practice Recommendations for managing Type 2 Diabetes in Primary Care. https://www.idf.org/elibrary/guidelines/128-idf-clinical-practicerecommendations-for-managing-type-2-diabetesin-primary-care.html.

36. Garber AJ, Abrahamson MJ, Barzilay JI, et al. Consensus statement by the American association of clinical endocrinologists and American College of Endocrinology on the comprehensive type 2 diabetes management algorithm-2017 executive summary. Endocr Pract. 2017;23(2):207-38.

37. Diabetes Canada Clinical Practice Guidelines Expert Committee, Lipscombe L, Booth G, Butalia S, et al. Pharmacologic glycemic management of type 2 diabetes in adults. Can J Diabetes. 2018;42(Suppl 1):S88-S103.

38. Mishra S, Ray S, Dalal JJ, et al. Management protocols of stable coronary artery disease in India: executive summary. Indian Heart J. 2016;68(6):868-73.

39. Bajaj S. RSSDI clinical practice recommendations for management of type 2 diabetes mellitus, 2017. Int J Diabetes Dev Ctries. 2018;38(Suppl 1):1-115.

40. Heerspink HJ, Johnsson E, Gause-Nilsson I, Cain VA, Sjöström CD. Dapagliflozin reduces albuminuria in patients with diabetes and hypertension receiving renin-angiotensin blockers. Diabetes Obes Metab. 2016;18(6):590-7.

41. Søfteland E, Meier JJ, Vangen B, Toorawa R, Maldonado-Lutomirsky M, Broedl UC. Empagliflozin as add-on therapy in patients with type 2 diabetes inadequately controlled with linagliptin and metformin: a 24-week randomized, double-blind, parallel-group trial. Diabetes Care. 2017;40(2):201-9.

42. Matsumura M, Nakatani Y, Tanka S, et al. Efficacy of additional canagliflozin administration to type 2 diabetes patients receiving insulin therapy: examination of diurnal glycemic patterns using continuous glucose monitoring (CGM). Diabetes Ther. 2017;8(4):821-7.

43. Cho HA, Jung YL, Lee YH, et al. Efficacy of body weight reduction on the SGLT2 inhibitor in people with type 2 diabetes mellitus. J Obes Metab Syndr. 2017;26(2):107-13.

44. Zaccardi F, Webb DR, Htike ZZ, Youssef D, Khunti K, Davies MJ. Efficacy and safety of sodium-glucose cotransporter- 2 inhibitors in type 2 diabetes mellitus: systematic review and network meta-analysis. Diabetes Obes Metab. 2016;18(8):783-94.

45. Johnston R, Uthman OA, Cummins E, et al. Canagliflozin, dapagliflozin and empagliflozin monotherapy for treating type 2 diabetes: systematic review and economic evaluation. Health Technol Assess. 2017;21(2):1-218.

46. Pinto LC, Rados DV, Remonti LR, Kramer CK, Leitao $\mathrm{CB}$, Gross JL. Efficacy of SGLT2 inhibitors in glycemic control, weight loss and blood pressure reduction: a systematic review and meta-analysis. Diabetol Metab Syndr. 2015;7(1):A58.

47. Monami M, Nardini C, Mannucci E. Efficacy and safety of sodium glucose co-transport-2 inhibitors in type 2 diabetes: a meta-analysis of randomized clinical trials. Diabetes Obes Metab. 2014;16(5):457-66.

48. Devi R, Mali G, Chakraborty I, Unnikrishnan MK, Abdulsalim S. Efficacy and safety of empagliflozin in type 2 diabetes mellitus: a meta-analysis of randomized controlled trials. Postgrad Med. 2017;129(3):382-92.

49. Xiong W, Xiao MY, Zhang M, Chang F. Efficacy and safety of canagliflozin in patients with type 2 diabetes: a meta-analysis of randomized controlled trials. Medicine (Baltimore). 2016;95(48):e5473.

50. Yang XP, Lai D, Zhong XY, Shen HP, Huang YL. Efficacy and safety of canagliflozin in subjects with type 2 diabetes: systematic review and meta-analysis. Eur J Clin Pharmacol. 2014;70(10):1149-58. 
51. Zhang M, Zhang L, Wu B, Song H, An Z, Li S. Dapagliflozin treatment for type 2 diabetes: a systematic review and meta-analysis of randomized controlled trials. Diabetes Metab Res Rev. 2014;30(3):204-21.

52. Liakos A, Karagiannis T, Athanasiadou E, et al. Efficacy and safety of empagliflozin for type 2 diabetes: a systematic review and meta-analysis. Diabetes Obes Metab. 2014;16(10):984-93.

53. Skolnik N, Bonnes H, Yeh H, Katz A. Dapagliflozin in the treatment of patients with type 2 diabetes presenting with high baseline A1C. Postgrad Med. 2016;128(4):356-63.

54. Roden M, Weng J, Eilbracht J, et al. Empagliflozin monotherapy with sitagliptin as an active comparator in patients with type 2 diabetes: a randomised, double-blind, placebo-controlled, phase 3 trial. Lancet Diabetes Endocrinol. 2013;1(3):208-19.

55. Stenlöf K, Cefalu WT, Kim KA, et al. Efficacy and safety of canagliflozin monotherapy in subjects with type 2 diabetes mellitus inadequately controlled with diet and exercise. Diabetes Obes Metab. 2013;15(4):372-82.

56. Wang Z, Sun J, Han R, et al. Efficacy and safety of sodium-glucose cotransporter- 2 inhibitors versus dipeptidyl peptidase- 4 inhibitors as monotherapy or add-on to metformin in patients with type 2 diabetes mellitus: a systematic review and metaanalysis. Diabetes Obes Metab. 2018;20(1):113-20.

57. Inagaki N, Kondo K, Yoshinari T, Takahashi N, Susuta Y, Kuki H. Efficacy and safety of canagliflozin monotherapy in Japanese patients with type 2 diabetes inadequately controlled with diet and exercise: a 24-week, randomized, double-blind, placebocontrolled, Phase III study. Expert Opin Pharmacother. 2014;15(11):1501-15.

58. Kaku K, Kiyosue A, Inoue S, et al. Efficacy and safety of dapagliflozin monotherapy in Japanese patients with type 2 diabetes inadequately controlled by diet and exercise. Diabetes Obes Metab. 2014;16(11):1102-10.

59. Ji L, Ma J, Li H, et al. Dapagliflozin as monotherapy in drug-naive Asian patients with type 2 diabetes mellitus: a randomized, blinded, prospective phase III study. Clin Ther. 2014;36(1):84-100.

60. Gupta S, Shaikh S, Joshi P, Bhure S, Suvarna V. Long-term efficacy and safety of empagliflozin monotherapy in drug-naïve patients with type 2 diabetes in Indian subgroup: results from a 76-week extension trial of phase iii, double-blind, randomized study. Indian J Endocrinol Metab. 2017;21(2):286.
61. Bolen S, Tseng E, Hutfless S, et al. Diabetes medications for adults with type 2 diabetes: an update [Internet]. Rockville (MD): Agency for Healthcare Research and Quality (US); 2016 Apr. (Comparative Effectiveness Reviews, No. 173.). https://www.ncbi. nlm.nih.gov/books/NBK362863/. Accessed 31 Aug 2018.

62. Shyangdan DS, Uthman OA, Waugh N. SGLT-2 receptor inhibitors for treating patients with type 2 diabetes mellitus: a systematic review and network meta-analysis. BMJ Open. 2016;6(2):e009417.

63. Mearns ES, Sobieraj DM, White CM, et al. Comparative efficacy and safety of antidiabetic drug regimens added to metformin monotherapy in patients with type 2 diabetes: a network metaanalysis. PLoS One. 2015;10(4):e0125879.

64. Lavalle-González FJ, Januszewicz A, Davidson J, et al. Efficacy and safety of canagliflozin compared with placebo and sitagliptin in patients with type 2 diabetes on background metformin monotherapy: a randomised trial. Diabetologia. 2013;56(12):2582-92.

65. Qiu R, Capuano G, Meininger G. Efficacy and safety of twice-daily treatment with canagliflozin, a sodium glucose co-transporter 2 inhibitor, added on to metformin monotherapy in patients with type 2 diabetes mellitus. J Clin Transl Endocrinol. 2014;1(2):54-60.

66. Ji L, Han P, Liu Y, et al. Canagliflozin in Asian patients with type 2 diabetes on metformin alone or metformin in combination with sulphonylurea. Diabetes Obes Metab. 2015;17(1):23-31.

67. Schumm-Draeger PM, Burgess L, Koranyi L, Hruba V, Hamer-Maansson JE, de Bruin TW. Twice-daily dapagliflozin co-administered with metformin in type 2 diabetes: a 16-week randomized, placebocontrolled clinical trial. Diabetes Obes Metab. 2015;17(1):42-51.

68. Bailey CJ, Gross JL, Hennicken D, Iqbal N, Mansfield TA, List JF. Dapagliflozin add-on to metformin in type 2 diabetes inadequately controlled with metformin: a randomized, double-blind, placebo-controlled 102-week trial. BMC Med. 2013;11(1):43.

69. Henry RR, Murray AV, Marmolejo MH, Hennicken D, Ptaszynska A, List JF. Dapagliflozin, metformin $\mathrm{XR}$, or both: initial pharmacotherapy for type 2 diabetes, a randomised controlled trial. Int J Clin Pract. 2012;66(5):446-56.

70. Häring HU, Merker L, Seewaldt-Becker E, et al. Empagliflozin as add-on to metformin in patients with type 2 diabetes: a 24-week, randomized, double-blind, placebo-controlled trial. Diabetes Care. 2014;37(6):1650-9. 
71. Ross S, Thamer C, Cescutti J, Meinicke T, Woerle HJ, Broedl UC. Efficacy and safety of empagliflozin twice daily versus once daily in patients with type 2 diabetes inadequately controlled on metformin: a 16-week, randomized, placebo-controlled trial. Diabetes Obes Metab. 2015;17(7):699-702.

72. Merker L, Häring $\mathrm{HU}$, Christiansen $\mathrm{AV}$, et al. Empagliflozin as add-on to metformin in people with Type 2 diabetes. Diabet Med. 2015;32(12):1555-67.

73. Li J, Gong Y, Li C, Lu Y, Liu Y, Shao Y. Long-term efficacy and safety of sodium-glucose cotransporter2 inhibitors as add-on to metformin treatment in the management of type 2 diabetes mellitus: a meta-analysis. Medicine (Baltimore). 2017;96(27):e7201.

74. Goring S, Hawkins N, Wygant G, et al. Dapagliflozin compared with other oral anti-diabetes treatments when added to metformin monotherapy: a systematic review and network meta-analysis. Diabetes Obes Metab. 2014;16(5):433-42.

75. Leiter LA, Yoon KH, Arias P, et al. Canagliflozin provides durable glycemic improvements and body weight reduction over 104 weeks versus glimepiride in patients with type 2 diabetes on metformin: a randomized, double-blind, phase 3 study. Diabetes Care. 2015;38(3):355-64.

76. Del Prato S, Nauck M, Duran-Garcia S, et al. Longterm glycaemic response and tolerability of dapagliflozin versus a sulphonylurea as add-on therapy to metformin in patients with type 2 diabetes: 4-year data. Diabetes Obes Metab. 2015;17(6):581-90.

77. Ridderstråle $\mathrm{M}$, Andersen KR, Zeller C, Kim G, Woerle HJ, Broedl UC, EMPA-REG H2H-SU trial investigators. Comparison of empagliflozin and glimepiride as add-on to metformin in patients with type 2 diabetes: a 104-week randomised, activecontrolled, double-blind, phase 3 trial. Lancet Diabetes Endocrinol. 2014;2(9):691-700.

78. Rosenstock J, Hansen L, Zee P, et al. Dual add-on therapy in type 2 diabetes poorly controlled with metformin monotherapy: a randomized doubleblind trial of saxagliptin plus dapagliflozin addition versus single addition of saxagliptin or dapagliflozin to metformin. Diabetes Care. 2015;38(3):376-83.

79. DeFronzo RA, Lewin A, Patel S, et al. Combination of empagliflozin and linagliptin as second-line therapy in subjects with type 2 diabetes inadequately controlled on metformin. Diabetes Care. 2015;38(3):384-93.

80. Mishriky BM et al. The efficacy of SGLT2 inhibitors compared with DPP-4 inhibitors as add-on therapy to metformin: a meta-analysis. Poster presented at ADA 2016. 131-LB.

81. Pacou M, Taieb V, Abrams KR, et al. Bayesian network meta-analysis to assess the relative efficacy and safety of canagliflozin in patients with type 2 diabetes mellitus (T2DM) inadequately controlled on metformin and sulphonylurea (MET $+\mathrm{SU})$. Value Health. 2013;16(7):A431.

82. Singh AK, Singh R. Combination therapy of sodium-glucose co-transporter-2 inhibitors and dipeptidyl peptidase- 4 inhibitors in type 2 diabetes: rationale and evidences. Expert Rev Clin Pharmacol. 2016;9(2):229-40.

83. Singh AK, Singh R. Sodium-glucose co-transporter-2 inhibitors and dipeptidyl peptidase-4 inhibitors combination therapy in type 2 diabetes: A systematic review of current evidence. Indian J Endocrinol Metab. 2016;20(2):245-53.

84. Kumar KP, Mohan V, Sethi B, et al. Efficacy and safety of canagliflozin in patients with type 2 diabetes mellitus from India. Indian $\mathrm{J}$ Endocrinol Metab. 2016;20(3):372.

85. Sosale B, Sosale AR, Kumar PM, Joshi SR. A prospective analysis of the efficacy and safety of sodium glucose cotransporter 2 inhibitors: real world evidence from clinical practice in India. J Assoc Phys India. 2016;64(9):40-4.

86. Baruah MP, Kalra S. Short-term outcomes of type 2 diabetes mellitus patients treated with canagliflozin in real-world setting. Indian J Endocrinol Metab. 2016;20(1):137.

87. Inzucchi SE, Zinman B, Wanner C, et al. SGLT-2 inhibitors and cardiovascular risk: proposed pathways and review of ongoing outcome trials. Diabetes Vasc Dis Res. 2015;12(2):90-100.

88. Schenk S, Harber MP, Shrivastava CR, Burant CF, Horowitz JF. Improved insulin sensitivity after weight loss and exercise training is mediated by a reduction in plasma fatty acid mobilization, not enhanced oxidative capacity. J Physiol. 2009;587(20):4949-61.

89. Mason C, Foster-Schubert KE, Imayama I, et al. Dietary weight loss and exercise effects on insulin resistance in postmenopausal women. Am J Prev Med. 2011;41(4):366-75.

90. Look AHEAD Research Group. Effect of a long-term behavioural weight loss intervention on nephropathy in overweight or obese adults with type 2 diabetes: a secondary analysis of the Look AHEAD randomised clinical trial. Lancet Diabetes Endocrinol. 2014;2(10):801-9. 
91. Franz MJ, Boucher JL, Rutten-Ramos S, VanWormer JJ. Lifestyle weight-loss intervention outcomes in overweight and obese adults with type 2 diabetes: a systematic review and meta-analysis of randomized clinical trials. J Acad Nutr Diet. 2015;115(9):1447-63.

92. Look AHEAD Research Group. Association of the magnitude of weight loss and changes in physical fitness with long-term cardiovascular disease outcomes in overweight or obese people with type 2 diabetes: a post hoc analysis of the Look AHEAD randomised clinical trial. Lancet Diabetes Endocrinol. 2016;4(11):913-21.

93. Look AHEAD Research Group. Effects of a long-term lifestyle modification programme on peripheral neuropathy in overweight or obese adults with type 2 diabetes: the Look AHEAD study. Diabetologia. 2017;60(6):980-8.

94. Espeland M. Reduction in weight and cardiovascular disease risk factors in individuals with type 2 diabetes: one-year results of the look AHEAD trial. Diabetes Care. 2007;30(6):1374-83.

95. Rosenwasser RF, Sultan S, Sutton D, Choksi R, Epstein BJ. SGLT-2 inhibitors and their potential in the treatment of diabetes. Diabetes Metab Syndr Obes. 2013;6:453-67.

96. Tosaki T, Kamiya H, Himeno T, et al. Sodium-glucose Co-transporter 2 inhibitors reduce the abdominal visceral fat area and may influence the renal function in patients with type 2 diabetes. Intern Med. 2017;56(6):597-604.

97. Bolinder J, Ljunggren Ö, Johansson L, et al. Dapagliflozin maintains glycaemic control while reducing weight and body fat mass over 2 years in patients with type 2 diabetes mellitus inadequately controlled on metformin. Diabetes Obes Metab. 2014;16(2):159-69.

98. Sevald CA, Jackson JD, McAna JF. SGLT2 inhibitors compared with sitagliptin as add-on therapy to metformin in type 2 diabetes: a systematic review and meta-analysis. Value Health. 2016;19(3):A197.

99. Cai X, Ji L, Chen Y, et al. Comparisons of weight changes between sodium-glucose cotransporter 2 inhibitors treatment and glucagon-like peptide-1 analogs treatment in type 2 diabetes patients: a meta-analysis. J Diabetes Investig. 2017;8(4):510-7.

100. Mohan V, Sandeep S, Deepa R, Shah B, Varghese C. Epidemiology of type 2 diabetes: Indian scenario. Indian J Med Res. 2007;125(3):217.

101. Joshi SR, Anjana RM, Deepa M, et al. Prevalence of dyslipidemia in urban and rural India: the ICMR-INDIAB study. PLoS One. 2014;9(5):e96808.
102. Shah VN, Mohan V. Diabetes in India: what is different? Curr Opin Endocrinol Diabetes Obes. 2015;22(4):283-9.

103. Unnikrishnan R, Anjana RM, Mohan V. Diabetes in South Asians: is the phenotype different? Diabetes. 2014;63(1):53-5.

104. Lilja M, Rolandsson O, Shaw JE, et al. Higher leptin levels in Asian Indians than Creoles and Europids: a potential explanation for increased metabolic risk. Int J Obes (Lond). 2010;34(5):878.

105. Ho SC, Tai ES, Eng PH, Ramli A, Tan CE, Fok AC. A study in the relationships between leptin, insulin, and body fat in Asian subjects. Int J Obes Relat Metab Disord. 1999;23(3).

106. Gao H, Salim A, Lee J, Tai ES, Van Dam RM. Can body fat distribution, adiponectin levels and inflammation explain differences in insulin resistance between ethnic Chinese, Malays and Asian Indians? Int J Obes (Lond). 2012;36(8):1086-93.

107. Abdullah N, Attia J, Oldmeadow C, Scott RJ, Holliday EG. The architecture of risk for type 2 diabetes: understanding Asia in the context of global findings. Int J Endocrinol. 2014;13:2014.

108. Kodama K, Tojjar D, Yamada S, Toda K, Patel CJ, Butte AJ. Ethnic differences in the relationship between insulin sensitivity and insulin response. Diabetes Care. 2013;36(6):1789-96.

109. Joshi SR. Diabetes care in India. Ann Glob Health. 2015;81(6):830-8.

110. Ma RC, Chan JC. Type 2 diabetes in East Asians: similarities and differences with populations in Europe and the United States. Ann N Y Acad Sci. 2013;1281(1):64-91.

111. Bolinder J, Ljunggren Ö, Kullberg J, et al. Effects of dapagliflozin on body weight, total fat mass, and regional adipose tissue distribution in patients with type 2 diabetes mellitus with inadequate glycemic control on metformin. J Clin Endocrinol Metab. 2011;97(3):1020-31.

112. Merovci A, Mari A, Solis C, et al. Dapagliflozin lowers plasma glucose concentration and improves $\beta$-cell function. J Clin Endocrinol Metab. 2015;100(5):1927-32.

113. Baker WL, Buckley LF, Kelly MS, et al. Effects of sodium-glucose cotransporter 2 inhibitors on 24-hour ambulatory blood pressure: a systematic review and meta-analysis. J Am Heart Assoc. 2017;6(5):e005686.

114. Berhan A, Barker A. Sodium glucose co-transport 2 inhibitors in the treatment of type 2 diabetes 
mellitus: a meta-analysis of randomized doubleblind controlled trials. BMC Endocr Disord. 2013;13(1):58.

115. Bailey CJ, Gross JL, Pieters A, Bastien A, List JF. Effect of dapagliflozin in patients with type 2 diabetes who have inadequate glycaemic control with metformin: a randomised, double-blind, placebocontrolled trial. Lancet. 2010;375(9733):2223-33.

116. Cha SA, Park YM, Yun JS, et al. A comparison of effects of DPP-4 inhibitor and SGLT2 inhibitor on lipid profile in patients with type 2 diabetes. Lipids Health Dis. 2017;16(1):58.

117. Chaturvedi V, Parakh N, Seth S, et al. Heart failure in India: the INDUS (INDia Ukieri Study) study. J Pract Cardiovasc Sci. 2016;2:28-35.

118. Nag T, Ghosh A. Cardiovascular disease risk factors in Asian Indian population: a systematic review. J Cardiovasc Dis Res. 2013;4(4):222-8.

119. Lee G, Oh SW, Hwang SS, Yoon JW, Kang S, Joh HK, Kwon H, Kim J, Park D. Comparative effectiveness of oral antidiabetic drugs in preventing cardiovascular mortality and morbidity: a network metaanalysis. PLoS One. 2017;12(5):e0177646.

120. Wu JH, Foote C, Blomster J, et al. Effects of sodiumglucose cotransporter-2 inhibitors on cardiovascular events, death, and major safety outcomes in adults with type 2 diabetes: a systematic review and metaanalysis. Lancet Diabetes Endocrinol. 2016;4(5):411-9.

121. Sonesson C, Johansson PA, Johnsson E, GauseNilsson I. Cardiovascular effects of dapagliflozin in patients with type 2 diabetes and different risk categories: a meta-analysis. Cardiovasc Diabetol. 2016;15(1):37.

122. Davies MJ, Merton K, Vijapurkar U, Yee J, Qiu R. Efficacy and safety of canagliflozin in patients with type 2 diabetes based on history of cardiovascular disease or cardiovascular risk factors: a post hoc analysis of pooled data. Cardiovasc Diabetol. 2017;16(1):40.

123. Salsali A, Kim G, Woerle HJ, Broedl UC, Hantel S. Cardiovascular safety of empagliflozin in patients with type 2 diabetes: a meta-analysis of data from randomized placebo-controlled trials. Diabetes Obes Metab. 2016;18(10):1034-40.

124. Neal B, Perkovic V, Mahaffey KW, et al. Canagliflozin and cardiovascular and renal events in type 2 diabetes. N Engl J Med. 2017;377:644-57.

125. Zinman B, Wanner C, Lachin JM, et al. Empagliflozin, cardiovascular outcomes, and mortality in type 2 diabetes. $\mathrm{N}$ Engl J Med. 2015;373(22):2117-28.

126. Raz I, Mosenzon O, Bonaca MP, et al. Declare-Timi 58: Participants' baseline characteristics. Diabetes Obes Metab. 2018.

127. Kosiborod M, Cavender M, Norhammar A. Lower rates of hospitalization for heart failure and allcause death in new users of SGLT2 inhibitors: the CVD-REAL study. 66th scientific session of the American College of Cardiology, Washington, DC. 2017 Mar 17, pp. 17-9.

128. Toulis KA, Willis BH, Marshall T, et al. All-cause mortality in patients with diabetes under treatment with dapagliflozin: a population-based, open-cohort study in the health improvement network database. J Clin Endocrinol Metab. 2017;102(5):1719-25.

129. Nyström T, Bodegard J, Nathanson D, Thuresson M, Norhammar A, Eriksson JW. Novel oral glucoselowering drugs are associated with lower risk of allcause mortality, cardiovascular events and severe hypoglycaemia compared with insulin in patients with type 2 diabetes. Diabetes Obes Metab. 2017;19(6):831-41.

130. Fioretto P, Zambon A, Rossato M, Busetto L, Vettor R. SGLT2 inhibitors and the diabetic kidney. Diabetes Care. 2016;39(Supplement 2):S165-71.

131. Wanner C, Inzucchi SE, Lachin JM, et al. Empagliflozin and progression of kidney disease in type 2 diabetes. N Engl J Med. 2016;375(4):323-34.

132. Kohan DE, Fioretto $\mathrm{P}$, Johnsson $\mathrm{K}$, Parikh S, Ptaszynska A, Ying L. The effect of dapagliflozin on renal function in patients with type 2 diabetes. J Nephrol. 2016;29(3):391-400.

133. Desai M, Yavin Y, Balis D, et al. Renal safety of canagliflozin, a sodium glucose co-transporter 2 inhibitor, in patients with type 2 diabetes mellitus. Diabetes Obes Metab. 2017;19(6):897-900.

134. Mudaliar S, Henry RR, Boden G, et al. Changes in insulin sensitivity and insulin secretion with the sodium glucose cotransporter 2 inhibitor dapagliflozin. Diabetes Technol Ther. 2014;16(3):137-44.

135. Polidori D, Mari A, Ferrannini E. Canagliflozin, a sodium glucose co-transporter 2 inhibitor, improves model-based indices of beta cell function in patients with type 2 diabetes. Diabetologia. 2014;57(5):891-901.

136. Ott C, Jumar A, Striepe K, et al. A randomised study of the impact of the SGLT2 inhibitor dapagliflozin on microvascular and macrovascular circulation. Cardiovasc Diabetol. 2017;16(1):26. 
137. Sosale B, Sosale A, Bhattacharyya A. Clinical effectiveness and impact on insulin therapy cost after addition of dapagliflozin to patients with uncontrolled type 2 diabetes. Diabetes Ther. 2016;7(4):765-76.

138. Charokopou M, McEwan P, Lister S, et al. Cost-effectiveness of dapagliflozin versus DPP-4 inhibitors as an add-on to metformin in the treatment of type 2 diabetes mellitus from a UK healthcare system perspective. BMC Health Serv Res. 2015;15(1):496.

139. Thomas MC. Renal effects of dapagliflozin in patients with type 2 diabetes. Ther Adv Endocrinol Metab. 2014;5(3):53-61.

140. Davies MJ, Trujillo A, Vijapurkar U, Damaraju CV, Meininger G. Effect of canagliflozin on serum uric acid in patients with type 2 diabetes mellitus. Diabetes Obes Metab. 2015;17(4):426-9.

141. Chino Y, Samukawa Y, Sakai S, et al. SGLT2 inhibitor lowers serum uric acid through alteration of uric acid transport activity in renal tubule by increased glycosuria. Biopharm Drug Dispos. 2014;35(7):391-404.

142. Gilbert RE, Mende C, Vijapurkar U, Sha S, Davies MJ, Desai M. Effects of canagliflozin on serum magnesium in patients with type 2 diabetes mellitus: a post hoc analysis of randomized controlled trials. Diabetes Ther. 2017;8(2):451-8.

143. Mosley JF, II LS, Everton E, Fellner C. Sodium-glucose linked transporter 2 (SGLT2) inhibitors in the management of type- 2 diabetes: a drug class overview. Pharm Ther. 2015;40(7):451.

144. Cefalu WT, Leiter LA, Yoon KH, et al. Efficacy and safety of canagliflozin versus glimepiride in patients with type 2 diabetes inadequately controlled with metformin (CANTATA-SU): 52 week results from a randomised, double-blind, phase 3 non-inferiority trial. Lancet. 2013;382(9896):941-50.

145. Filippatos TD, Liberopoulos EN, Elisaf MS. Dapagliflozin in patients with type 2 diabetes mellitus. Ther Adv Endocrinol Metab. 2015;6(1):29-41.
146. Schwartz AV, Vittinghoff E, Bauer DC, et al. Association of BMD and FRAX score with risk of fracture in older adults with type 2 diabetes. JAMA. 2011;305(21):2184-92.

147. Tang H, Zhang J, Song Y. Adverse effects and safety of SGLT2 inhibitor use among patients with type 2 diabetes: findings from RCT evidence. N A J Med Sci. 2017;10(2):78-82.

148. Taylor SI, Blau JE, Rother KI. Possible adverse effects of SGLT2 inhibitors on bone. Lancet Diabetes Endocrinol. 2015;3(1):8-10.

149. Watts NB, Bilezikian JP, Usiskin K, et al. Effects of canagliflozin on fracture risk in patients with type 2 diabetes mellitus. J Clin Endocrinol. 2016;101(1):157-66.

150. Barnett AH, Mithal A, Manassie J, et al. Efficacy and safety of empagliflozin added to existing antidiabetes treatment in patients with type 2 diabetes and chronic kidney disease: a randomised, double-blind, placebo-controlled trial. Lancet Diabetes Endocrinol. 2014;2(5):369-84.

151. Ljunggren Ö, Bolinder J, Johansson L, et al. Dapagliflozin has no effect on markers of bone formation and resorption or bone mineral density in patients with inadequately controlled type 2 diabetes mellitus on metformin. Diabetes Obes Metab. 2012;14(11):990-9.

152. Ruanpeng D, Ungprasert P, Sangtian J, Harindhanavudhi T. Sodium-glucose cotransporter 2 (SGLT2) inhibitors and fracture risk in patients with type 2 diabetes mellitus: a meta-analysis. Diabetes Metab Res Rev. 2017;33(6):e2903.

153. Tanaka A, Node K. Increased amputation risk with canagliflozin treatment: behind the large cardiovascular benefit? Cardiovasc Diabetol. 2017;16(1):129.

154. Kohler S, Zeller C, Iliev H, Kaspers S. Safety and tolerability of empagliflozin in patients with type 2 diabetes: pooled analysis of phase I-III clinical trials. Adv Ther. 2017;34(7):1707-26. 